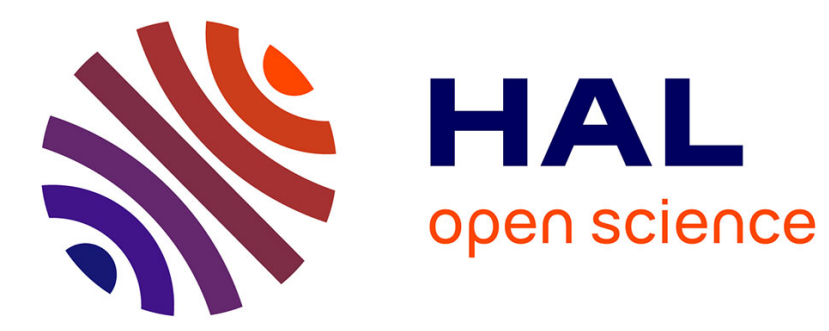

\title{
Paysage et géographie physique globale. Esquisse méthodologique
}

Georges Bertrand, Jean Tricart

\section{To cite this version:}

Georges Bertrand, Jean Tricart. Paysage et géographie physique globale. Esquisse méthodologique. Revue Géographique des Pyrénées et du Sud-Ouest, 1968, 39 (3), pp.249-272. 10.3406/rgpso.1964.4776 . hal-02611126

\section{HAL Id: hal-02611126 \\ https://hal.science/hal-02611126}

Submitted on 18 May 2020

HAL is a multi-disciplinary open access archive for the deposit and dissemination of scientific research documents, whether they are published or not. The documents may come from teaching and research institutions in France or abroad, or from public or private research centers.
L'archive ouverte pluridisciplinaire HAL, est destinée au dépôt et à la diffusion de documents scientifiques de niveau recherche, publiés ou non, émanant des établissements d'enseignement et de recherche français ou étrangers, des laboratoires publics ou privés. 


\section{Paysage et géographie physique globale. Esquisse méthodologique} Georges Bertrand, Jean Tricart

\section{Citer ce document / Cite this document :}

Bertrand Georges, Tricart Jean. Paysage et géographie physique globale. Esquisse méthodologique. In: Revue géographique des Pyrénées et du Sud-Ouest, tome 39, fascicule 3, 1968. pp. 249-272;

doi : https://doi.org/10.3406/rgpso.1968.4553

https://www.persee.fr/doc/rgpso_0035-3221_1968_num_39_3_4553

Fichier pdf généré le 06/04/2018 


\section{Résumé}

L'étude globale des paysages à dominante physique devrait être l'une des préoccupations majeures du naturaliste et du géographe. La méthode proposée tient compte à la fois de l'échelle temporo-spatiale, de la physionomie et de la dynamique des paysages. Le système taxonomique comporte six unités synthétiques emboîtées : la zone, le domaine, la région naturelle, le " géosystème ", le " géofaciès " et le " géotope ». Chacune de ces combinaisons dialectiques comporte un potentiel écologique, une exploitation biologique et se définit essentiellement par un "système d'évolution » qui intègre le système d'érosion traditionnel, la dynamique proprement biologique et l'action anthropique. Une typologie dynamique permet de classer les paysages en fonction de leur mobilité par rapport au climax général (évolution progressive, régressive, stabilité). Cette méthode se complète par une cartographie systématique des paysages au niveau des géosystèmes et des géofaciès qui débouche tout naturellement sur les problèmes d'aménagement de l'espace non urbanisé.

\section{Resumen}

Paisaje y geografía física global : Ensayo de metodología. - El estudio sintético de los paisajes en que predomina lo físico tendría que ser una de las mayores preocupaciones del naturalista y del geógrafo. El método que aquí se propone tiene en cuenta la escala temporo-espacial, la fisionomía y la dinámica de los paisajes. El sistema de classificación consta de seis unidades sintéticas sobrepuestas : la « zone », el « domaine », la « région naturelle », el " géosystème », el " géofaciès » y el " géotope ». Cada una de estas combinaciones dialécticas incluye un potencial ecológico, una explotación biológica y se define esentialmente por un sistema de evolución que asimila el sistema de erosión tradicional, la dinámica meramente biológica y la acción antrópica. Una tipología dinámica permite clasificar los paisajes según su mobilidad en relación con el climax general (evolución progressiva, regressiva, estabilidad). Viene rematado este método por una cartografía sistemática de los paisajes a la altura de los " géosystèmes " y de los "géofaciès ", la cual empalma naturalmente con los problemas de la organisación del espacio no urbanizado. 


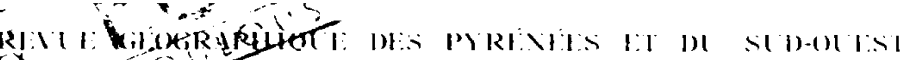

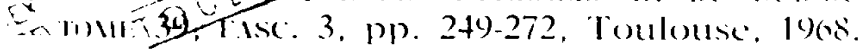

\section{Paysage et géographie physique globale Esquisse méthodologique (1) \\ par Georges Bertrand*}

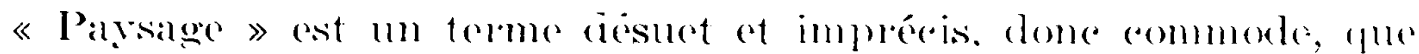
chacmon ulilise à sa guise, le plus somvent en y adjoignant un qualifi-

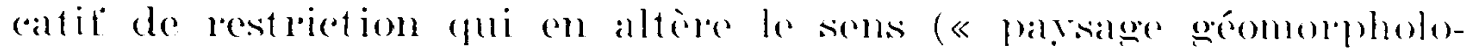

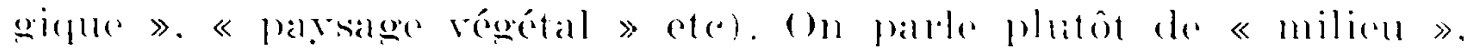

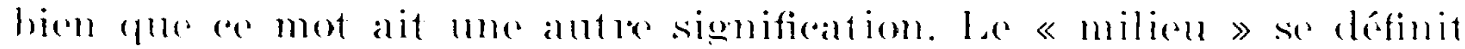

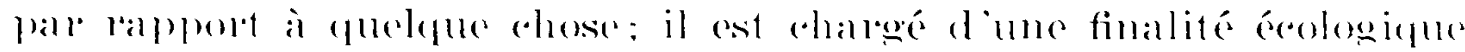

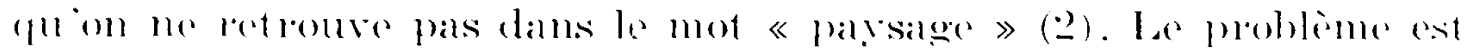

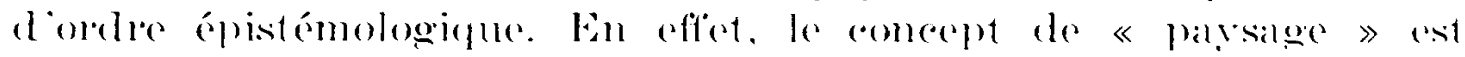

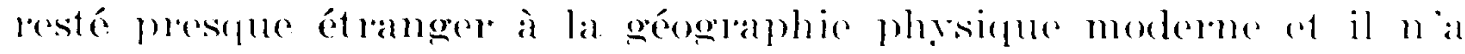

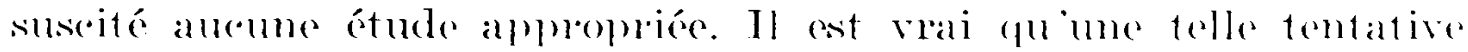
implique une réflexion méthodologique ot des recherches spéedifines

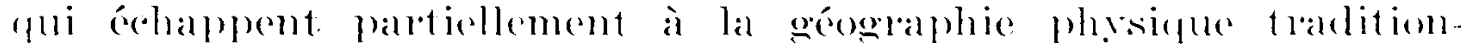

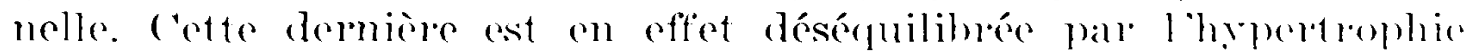
de la recherehe wémomphologique ot par de glaves alremes, en partieulier dans le domaine des seiencess hiogengraphiques. Enfin.

$\because$ Charge denscignement a la Faculte des Lettres de Toulouse.

(1) Ce travail a été présente le it nowembre 1967, à l'Institut de Géographic Daniel Faucher (Toulouse), au cours d'une rénion du Groupe de recherehe de Geographic physique que dirige $M$. le Professeur Tallitiltr. Nous remercions tres chaleureusement les naturalistes et les géographes qui ont participe au débat. Nous avons tenu compte de leurs observations eq de lents critiques. Deux communications sur ke meme sujet ont ete faites, l'une devant la Commission de Biogéographic el de Climatologie aux Journés géoglat. phiques de Bordeaux (mars 1968). l'autre at loceasion du Colloque de Taxonomic qui s'est tenu a l'Feole Normale Superieure du boulevard Jourdan, Paris, mai 1968.

(2) Milieu : "Espace qui entoure immédiatement les cellules ou kes organismes vivants et avec lequel les etres rivants réalisent des cehanges constants de matiere et d'energie..." Grand Larousse Encrelopedique, 1. 7, p. 358. 


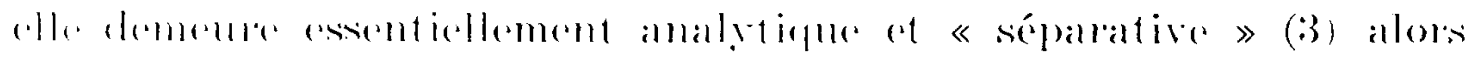

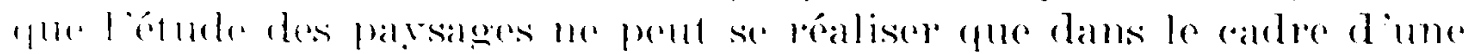

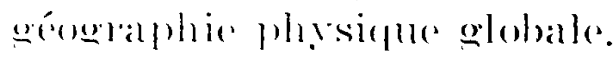

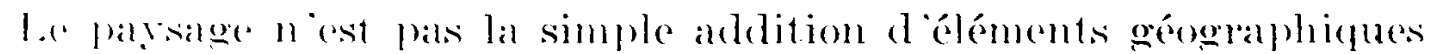

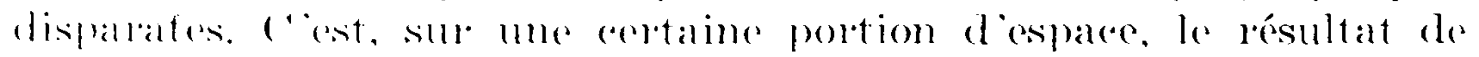

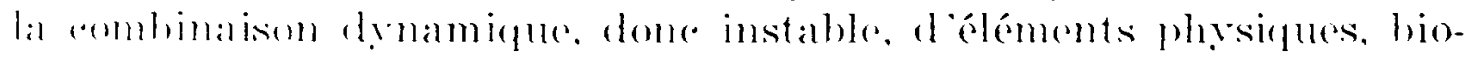
leviques ot anthrophiques qui on réagissant dialectiquemont les uns stal les alltere font du parsage un ensemble unique et indissociable an perpertuelle érolution. Ia dialectique type-individu est le fondement même de la méthode de recherche.

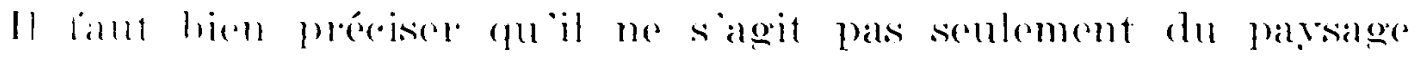

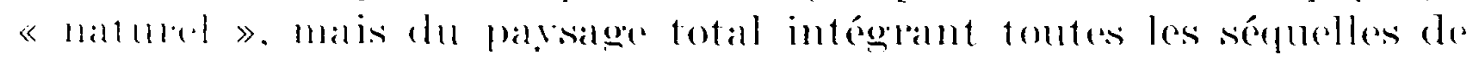
lantion anthropiefue. (ependant, on laissera provisoirement de côté

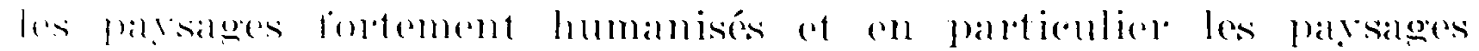

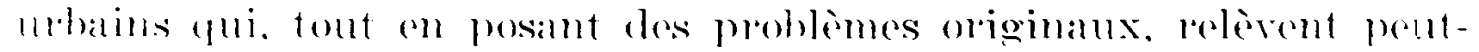

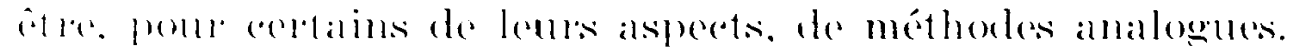

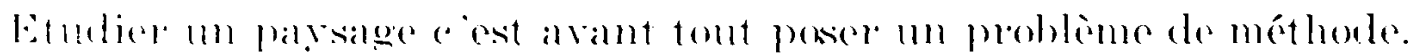
1. Axpesé pui suit porte suceessivement sur la taxomomie. la drana-

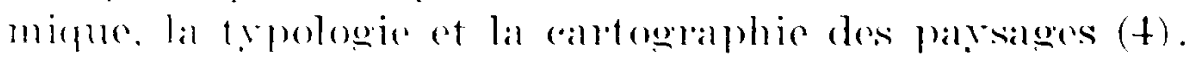

\section{L'analyse du paysage}

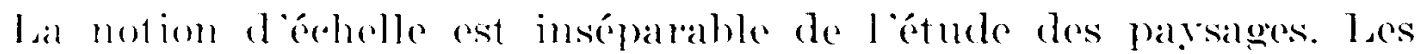
échelles temporo-spatiales d inspiration géomomphologique de $A$. Cail-

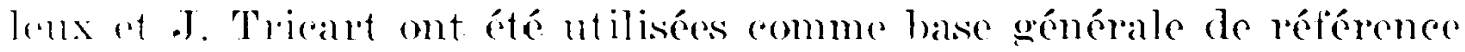
pellr tous les phénomènes géographiques (lordre de grandeur est indigue ontre barentheses, on abrége (i. I, (2. II, (i. III. ete.) (5).

1. Les classifications élémentaires. - Chalque discipline spécoialisée

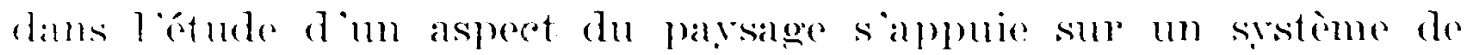
déconflage plus ou moins systématique formé d 'unités homogemes (chu moins relativement à l'échelle considérée) at hiéranchisées. qui semboitent les unes dams les autres. Ta classifieation phỵtogéogralphique de II. Aausion : ETAGE (ex : méditeranén) - SERIE

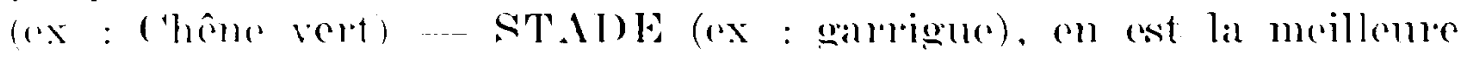

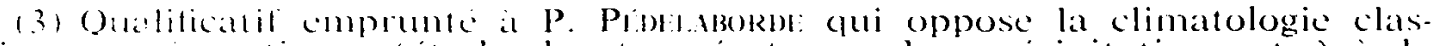
siche "spatrative " (etude des températures, cles precipitations etc.) it la clinatologie " drnamique " (itude globale des masses d'air). Introdaction it l'tule scientifique du climat, Paris, C. D. U., 1955, p. 3.

(t) Cette mise au point a été essentiellement inspirée par les recherches sul le terain on vue de la préparation d'une these de doctorat d'F.tat : les navises cantabriques: Picos de Furopa et Montaña de Léon (Nord-Ouest ac l'Funagne). 


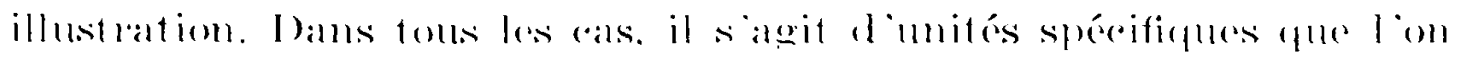

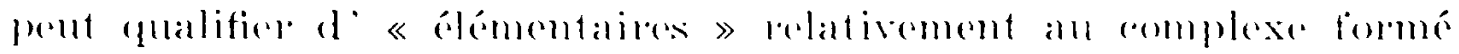

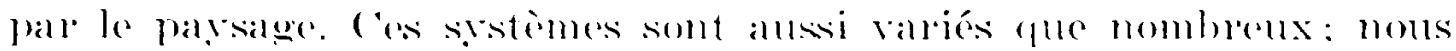

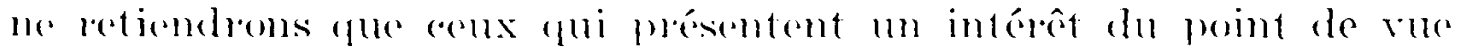
de la taxomomie des paysages.

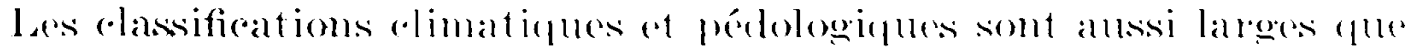

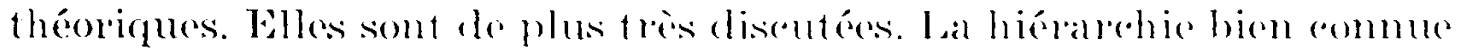

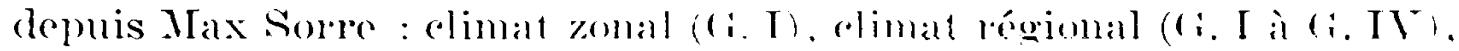

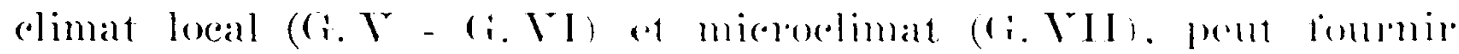

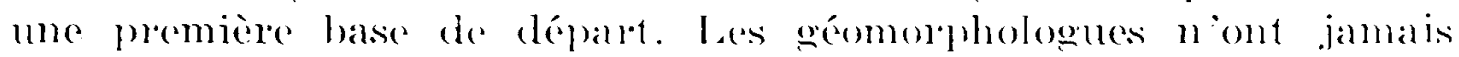
manifesté beancoup d intérêt pont les questions taxomomiques. Citons seulement la classification morpho-structumale presenté pall

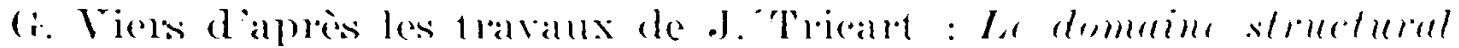
(ex : l'Europe herernienno, (i. III) - - La régiom structurale (ex : l'Ardenne. (a. IV) - Lumite structurele (ex : un anticlinal pre-

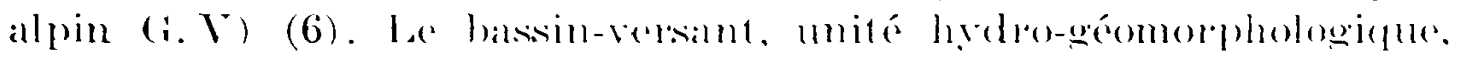
eorrespond à une diseontinute essentiolle du paysalere mais il est heterogene par defintion of la limite aral est tomjours diffieile is établir. Enfin, les paysages dits « physigfues toujours largement remolelés par lexploitation anthropique. Le

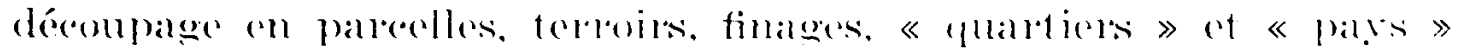

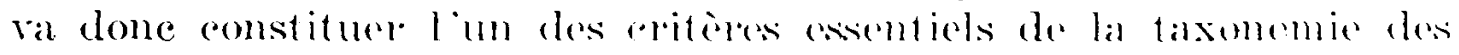
palisages $(\vec{T})$.

Cependant, la meilleure apporehe du mohlome est fomenie par la

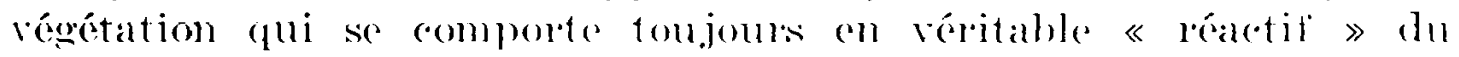

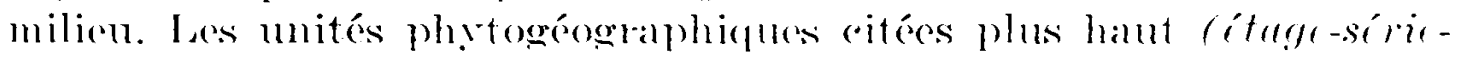
strede) correspondent à dos masses régétales partaitement dófinies. aussi bien sur le plan phisionomique que sur le plan dymamique. ha phytosociologie moderne à mientation șnéeologique vient halpmonieusement completer a sisteme en permettant do délimiter des mités homogenes du point de rue floristipue associations et seroupements régétaux. li. VT à (i. VII).

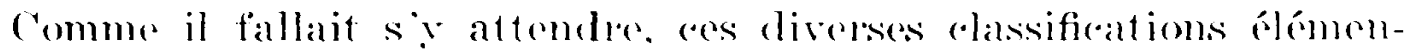

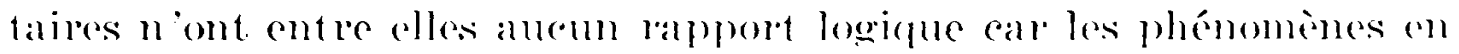
cause appartionnent à des orderes géographiques diflepents. Cortains spécolalistes ont réalisé des regeroupements partiels qui romstituent dé.ji une première étape vers la definition des paysages. Dans ae

(5) J. Treart, Principes at Mélgodes de la Gémorphologic. Paris, Masson. 1965, pp. 79-90. Voir aussi l.. Gluvialld, Degré de régiomalité. Bull. Soc. Géol. Fr., 1952.

(6) G. Viers, Fiéments de géomorphologié. Paris, Nathan, 1967, pp. 27-29.

(7) Terminologie utilise par R. BRt NeT dans des études à paraitre : $L a$ notion de quartice rural. Bull. A. G. F., 1968 et Rev. géogr. Pyr. S.-O., 1968. 
domainr. les hiogénganphes ont dromis lomgtemps précéde les géoelatphess.

2. Les combinaisons bio-écologiques. -.. la hiorénose ast « :II

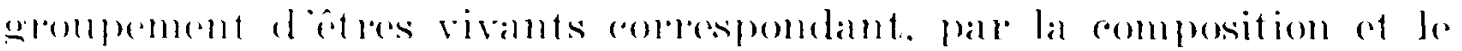

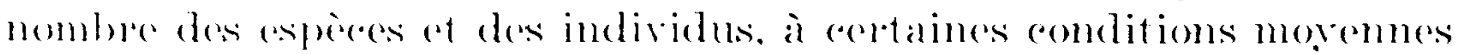

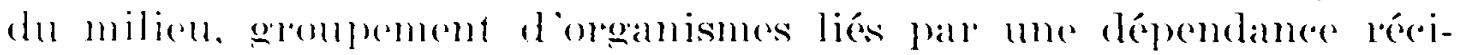

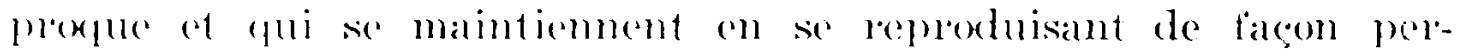
manente

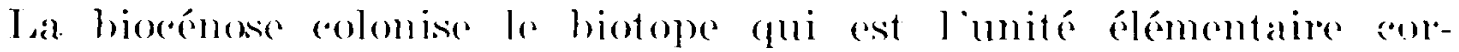
respendant an plus petit ensomble homegene du milieu phrsieo-

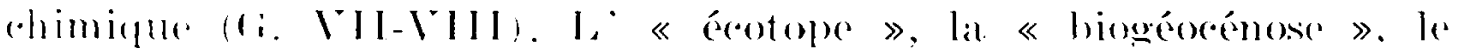

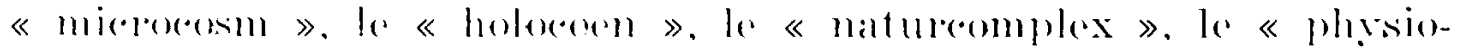
foje». le « geoform » ete. expriment aree quelques nuanees of des fortumes diverses. lam lóalite assog voisine (9).

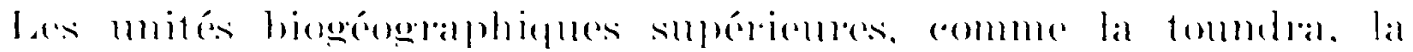

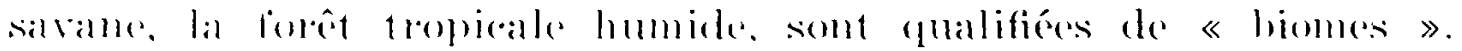
( somt des masses relativement homogones de régetallx of dani-

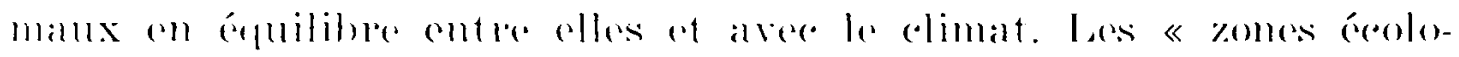

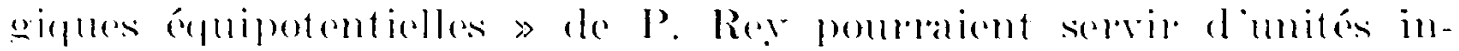

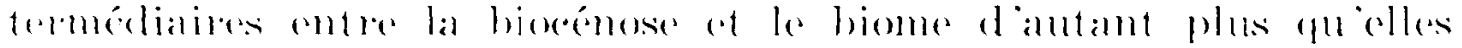

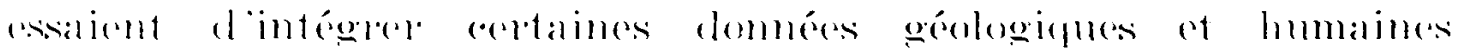

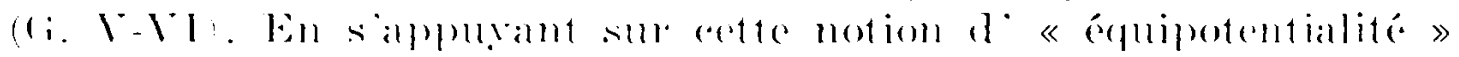

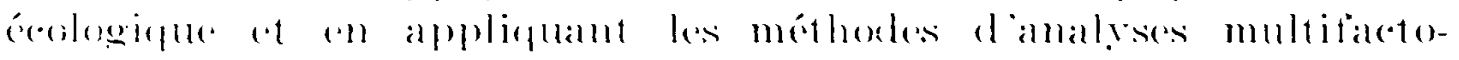

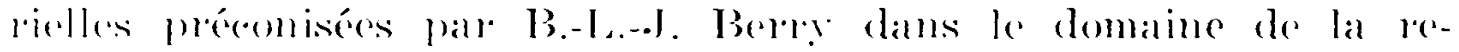

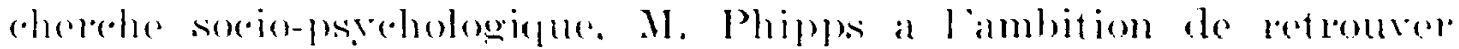
les structules du « parsage hiogéoglaphique » ot de définir mathé-

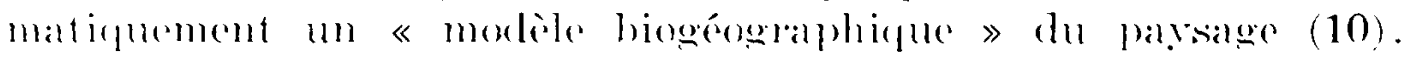

les hogrographes modelnes somt alles encore plus loin dams la

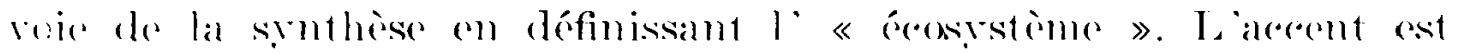

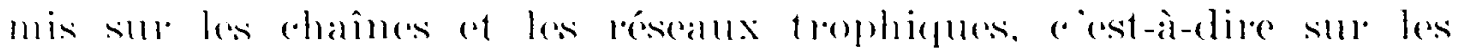
lions alimentaires qui missent les individus of les commmantes

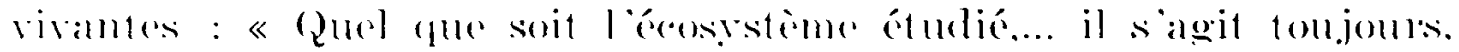

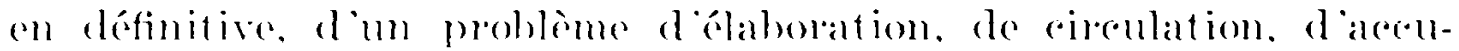
mulation of de transformation dónergie potenticlle par laretion

(8) M. Axcintle, Coms de biogcographic animale professé au Centre de moisieme crele de biogcographic de la Faculte des Sciences de Toulouse (annic 1963-1964).

(9) Cl. plus parliculionment Edward S. Kormoxis, Readings of ecologs, New-Jersey, 1965, 220 p.

(10) P. RIY, Ciblussti. ArI.s, Les bases biogéographiques de la restantation forcistiere et pastorale dans le département de l'Aude (Corbières, Razés, Piège). Touluuse, 1961 (C. N.R. S., Service de la Carte de la régétation, 39 p. ronco.). M. Phipps, Introciacion an concept de modele biogéographique. Actes II Simposium Internat. Phot. Interpretation, Paris, 1966, IV-2, pp. $41-49$. 
des ôtres vivants ot de lelll métabolisme » (11). Parmi les meil-

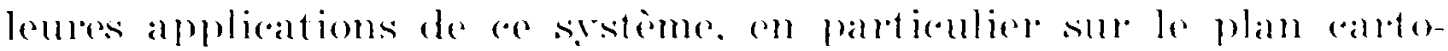

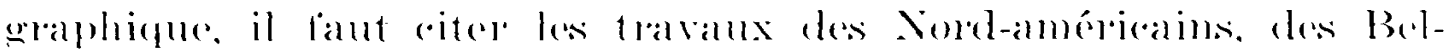

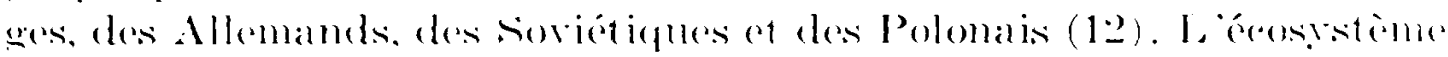
n'a ni échelle, ni support spatial bien défini. Il est l'oéam. mais

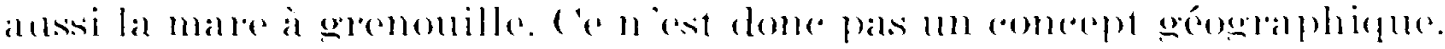

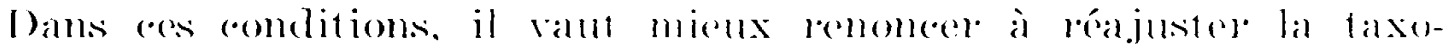

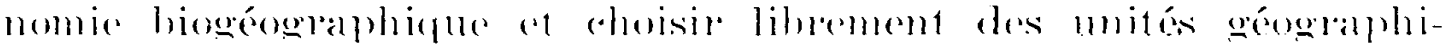

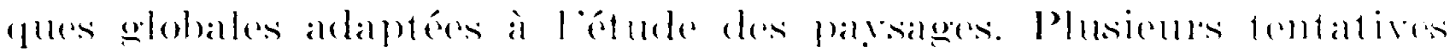

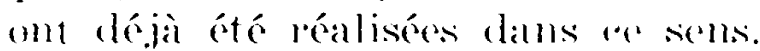

3. Les premières synthèses géographiques. -- lii « régioll mi-

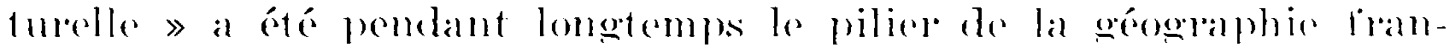

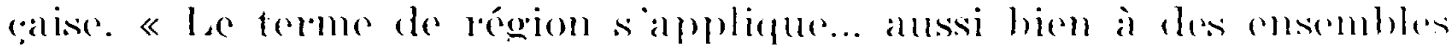
phesiques. structuraux on elimatiques. gu à des domaines distin-

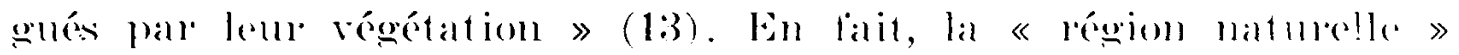
échappe a toute définition ratiommelle anssi hien pont he antemu

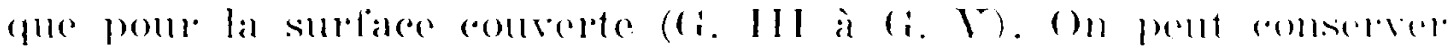

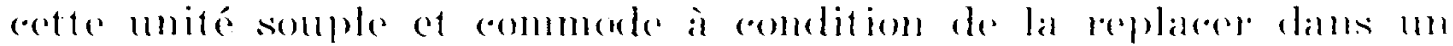

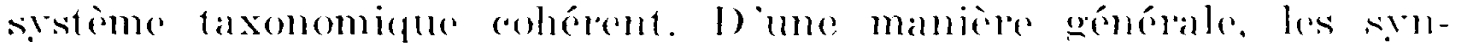

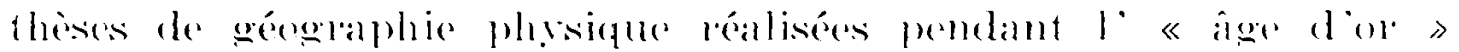

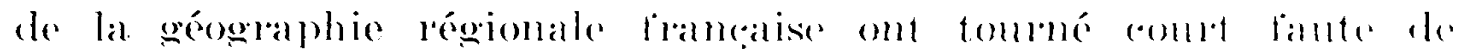

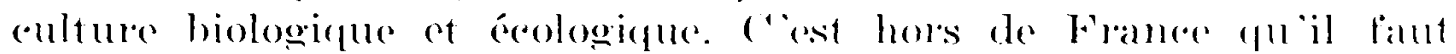
rhereher les rales tentatives pour apmohender lo payalge dans sa totalite. Nous laisselons pour l instant de coté fons les décompanes plus on moins andenomiques liés an « land-use » britamnique ou au « soil-surver » nolrd-américain.

I a notion de « Landschali » domine toute la géographic enerma-

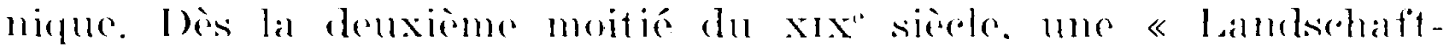

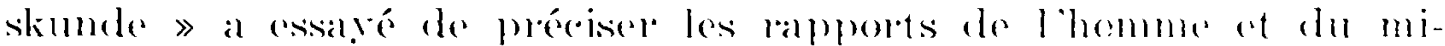
lieu. Io déterminisme abrupt de rette science du paysage a rol-

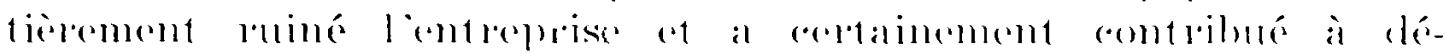

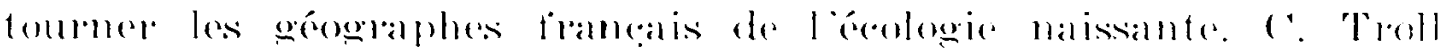

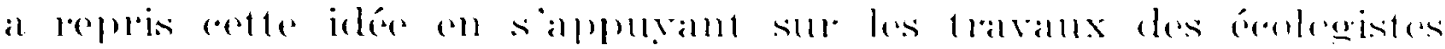

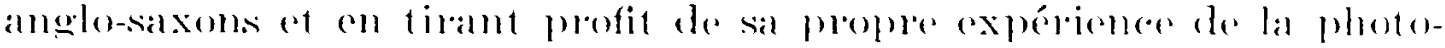

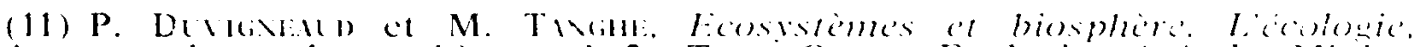
science moderne de swnhese (vol. 2). Trav. Centre Ecologic genciale, Minist. Education Nationale, Bruxelles. 1962.127 p.

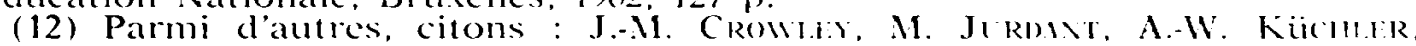

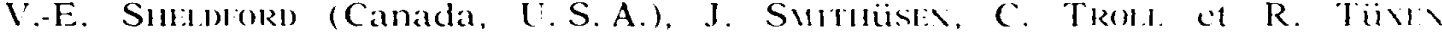

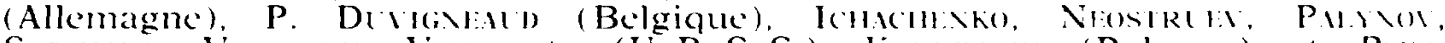

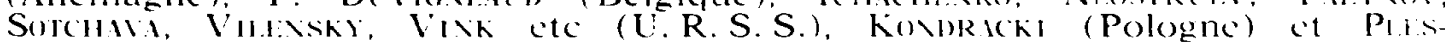

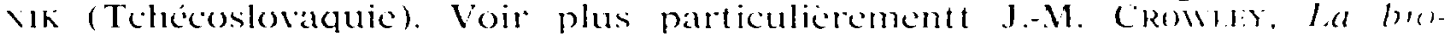

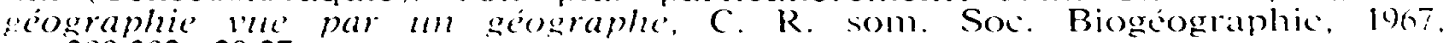
II" $380-382,20-27$.

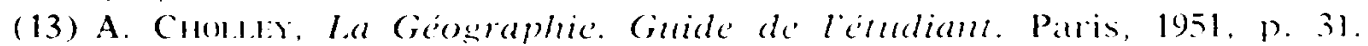


interprétation (14). Il a jeté les halses do la « Tandschaftsökologite » yui est une efude du parsage du point de vue écologigue. las

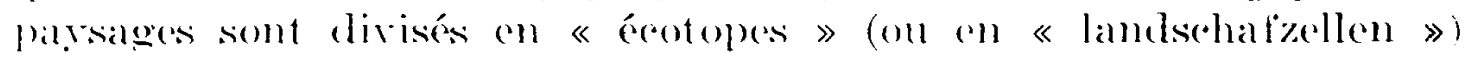
qui sont des unités tout à lait companables a l'écoststeme. Cotte méthole represente un progres déeisif sur les etudes forgmentaires des géographes of des hiogeographes. al elle regeompe toms

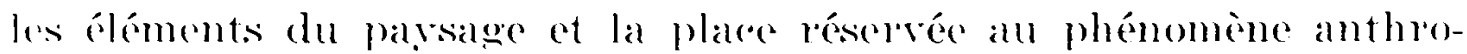
piefur y est particulieremont importante. Cependant, il sagit davantage dime attitude d'esplit que diune méthode d'étude soienlifiquemont établie. Ia définition des «écotopes » reste imprécise ot la hiérarehisation des facteurs nest pas évoquée. Aucune typologie sistématique ne permet de poser elabement le probleme de la representation cartoglaphique. 11 sage at an somme diune méthode plus écologique que géographique.

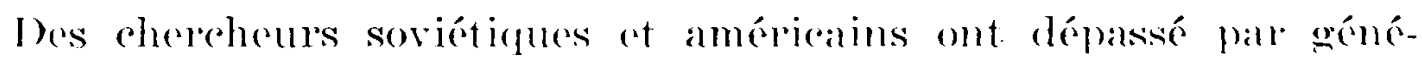

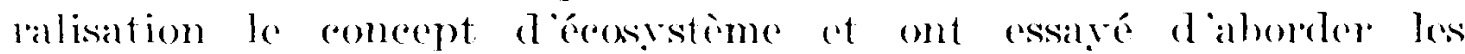
paraloes sous laspect sleictement quantitatif (14). Le paysage (nt considéré romme un systeme énergétique dont lätude se pose en termes de transformation of de productivite biochimigue. A « acochimical landscape » enrichit ot simplifie a la fois la notion traditionnelle de « paysalge 》. Mais les spédalistes enx-mêmess se demandent comment ils pourront mesurele la photosynthèse mise a part. les transformations d'enelogie an niveau des éléments autres que les régétaux et en partieulier au niveau de la miclotaune. le calcul même approché du bilan énerótique d'un parsage n'est pas encore passible. Pour linstant. le principal intérêt du « geochemical landscape » est daboutip a nue typologie dyomamique des paysages en fonction de la migration des substancos géochimiques. On distingue trois categonies de paysages : mu type « residucl » (stable), un trpe « de transit 》 (perte de substance) et $11 n$ type d" « acemmulation ». Sous ume formulation diffépente, on retrouve la bio-rhexistasie de II. Frlant que cortains géperaphes tentent dadapter à la géographie physique (15). I co niveau de

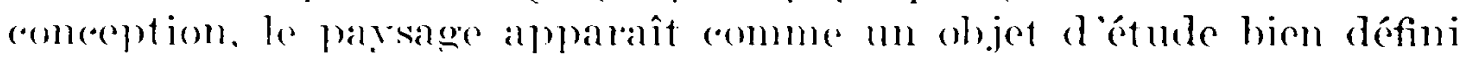
qui alpelle une mise an point méthodologique.

(1t, C. Trom, Landscape ecology. Public of the 1. T. C. UNESCO Centre for integrated Sumess, 1966 , Dellt $5.4,23 \mathrm{p}$.

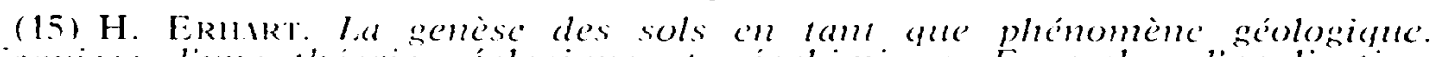

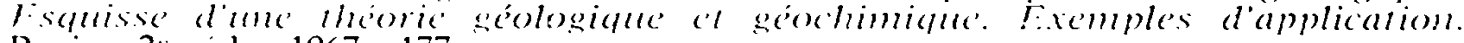
Paris, 2" id., 1967, 177 p. 


\section{La synthèse du paysage}

Tous les découpages géographiques sont alphitraires ot « il at impassible de trourer un sistime génépal de lespares qui resperete

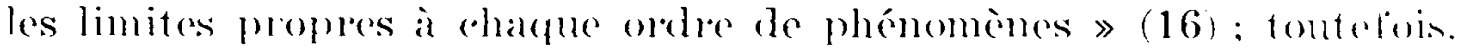
on pellt rovisacere une taxomomie des paysages à dominante physique à comelition din fixar des malntenant les limitos.

1" Le découpage ne doit jamais ettre considéré comme une fin an soi, malis semlement eomme un moxen dapploche par rappopt

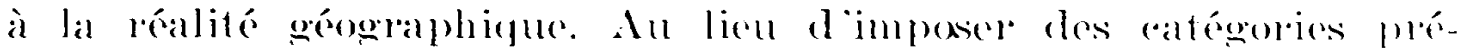
etablies it sageit de rechereher les discomtinutes objeretives du pariage.

20" Il faut unc fois pour toutes renoncer à déterminey des unitós synthétiques sur la base d’un eompromis à partir des unites elémentailes. Lin effet, ea serait une mauraise méthode que de vomloir superposer. soit par la méthode cartographique direceles soit par la méthoxle mathématigue (systeme de la « grille 》). He maximum d'unités élémentaires pour en déager me unité « movenne » qui nexprimerait aueume réalité du fait de la strueture dialeretique des paysages. Au contraire. il faut taillev directement dans le parsalge global tel qu il se présente. Certes, le découpage sela plus grassier. mais les combinaisons of les rapports cuter les chéments ainsi que les phénomènes de convergenence n'en apparaîtront que plus elatement. La sinthèse vient ici heureusement relalyel lanalyse.

3" Ie sisteme taxonomique doit permettre de classel les pariatges en fonction de l’échelle, e'est-ì-die de les situel dans la double

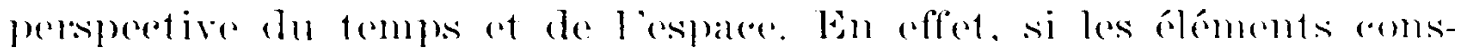

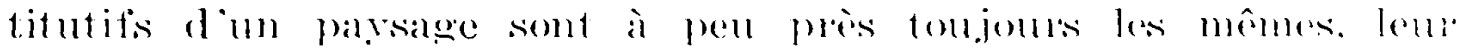
place respective of surtout loms manifestations all soin des antl-

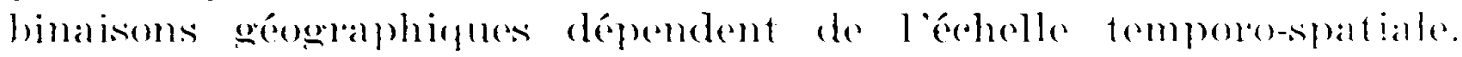
Il existe pour rhaque ordre de phénomènes des «souils de mani-

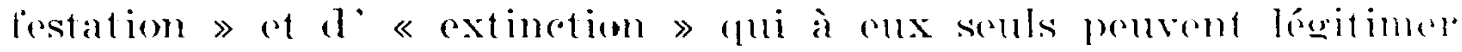
le découpage systématique des paysages en unités hierarehisées (17).

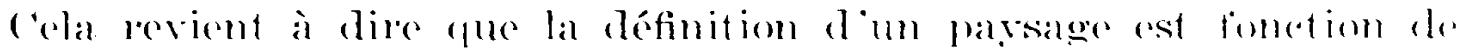

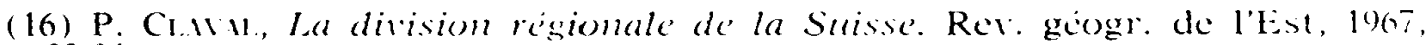
pp. 83-94.

(17) R. Brivet, Les phénomines de discontimite en géographie (These complem. Toulouse, 1965, pp. 22-28), sur exemplaite ronćoté (En cours de publication dans les Memoires et Documents du comire de Recherehes el Documentation cartographicples et geographiques du C.N.R.S. S. 
léchelle. Au soin d’un même ststeme taxomomigue, les éléments

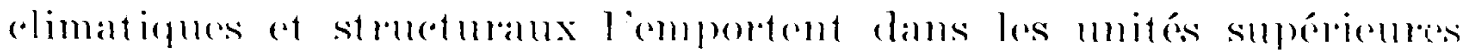

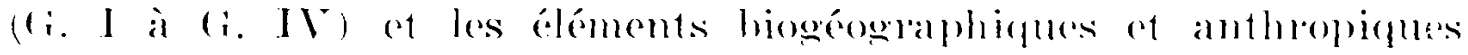

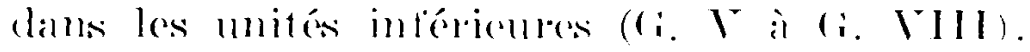

las sisteme de elassifieation qui a be finalement retenu comporte

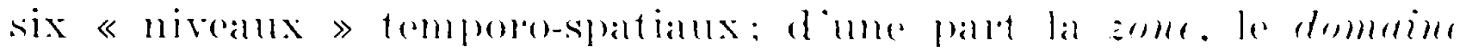

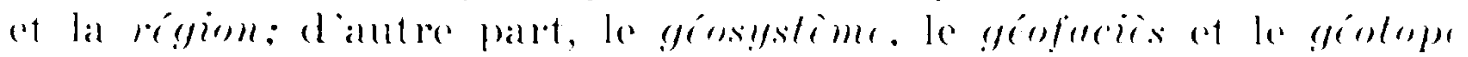
(tableatu ci-contres).

1. Les unités supérieures. - I des recherohes so sont limitées aux unités inférioures. cepondant, il a paru nécossaire de présentor un systeme taxomomique romplet. Pout les unites supépienres, il suffit

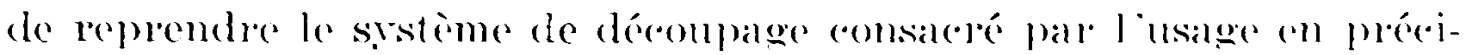

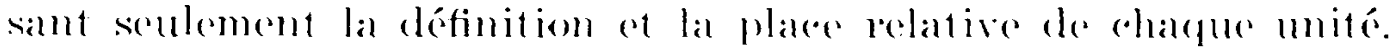

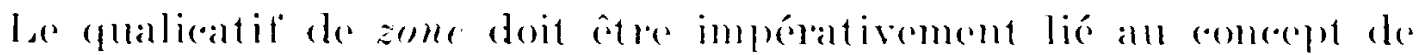
zonalite planetalre. Il esi dome léservé anx ensembles de promione

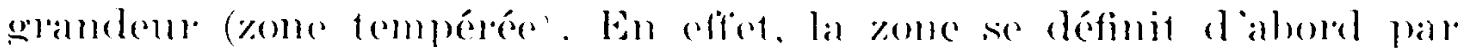

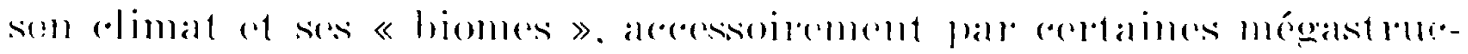

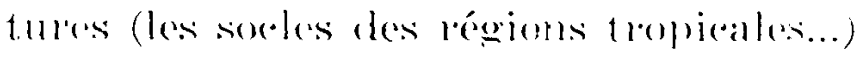

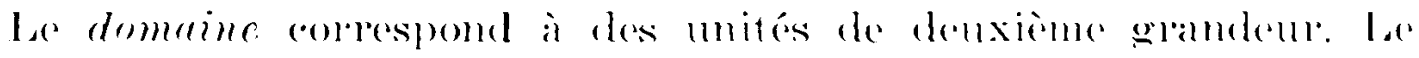

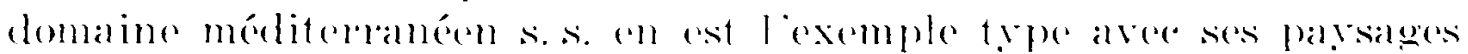
vigondensement individualisés. 1) la mêne maniòre, on définit un domaine cantabrique caractérise par none cortaine combinaison de reliefs montagneux of de colimats ocóaniques. La définition du domaine doit rester suffisamment somple pour permettre des regeroupements diffépents dans lespuels la hiéarehie des facteurs peut ne pas être la même (domaine alpin. domaine atlantique européen...).

La régionn neturelle, déjà présentée. se siture ontro la troisiome et

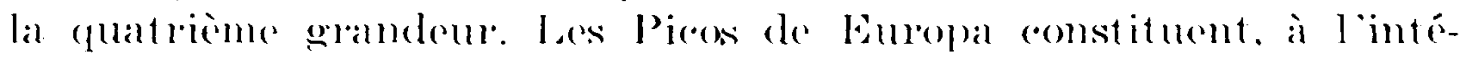

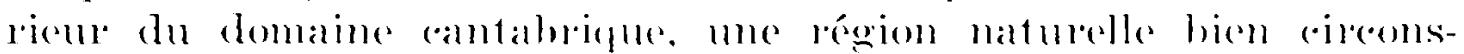

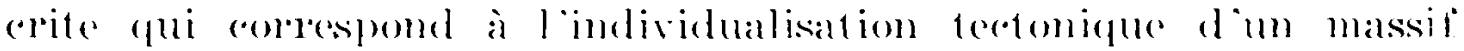

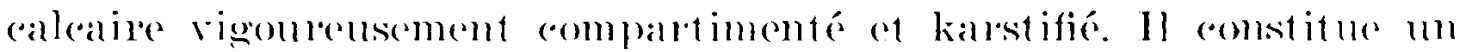

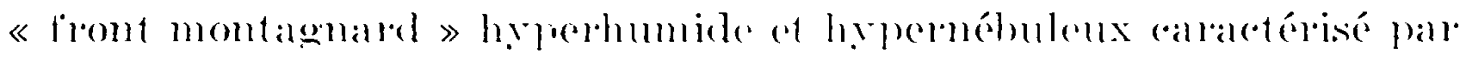

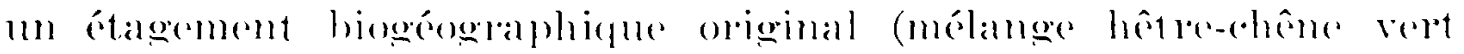

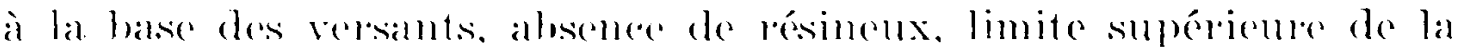

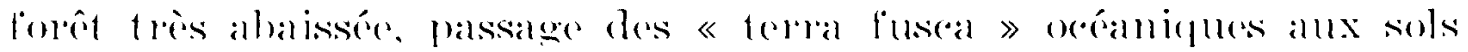
alpins humigules).

2. Les unités inférieures. - Il a fallu crép de tolltes pièces les

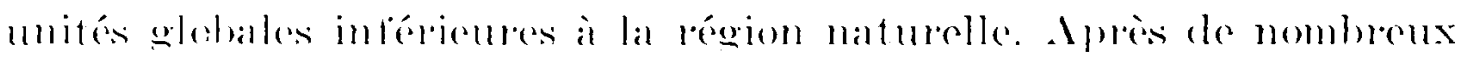

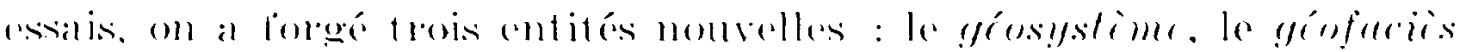

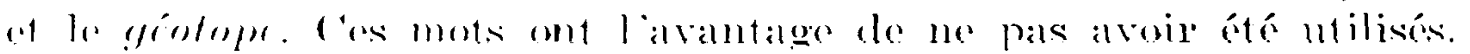

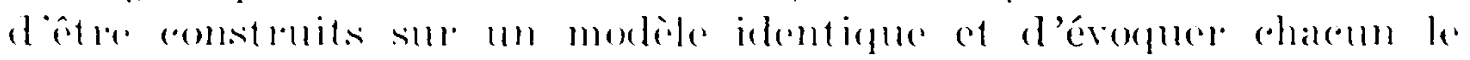




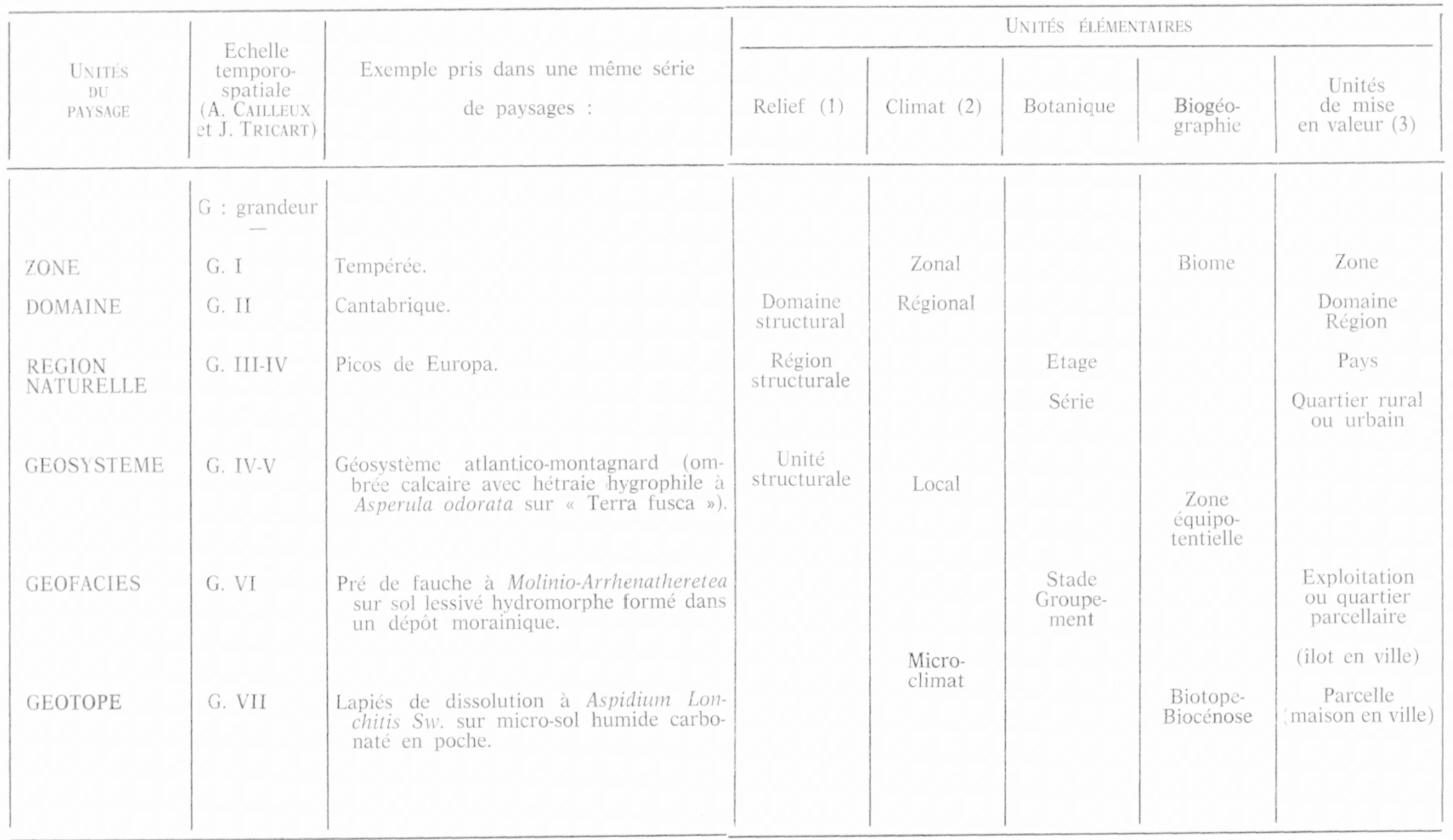

N. B. : Les correspondances entre les unités sont très approximatives el données seulement à titre d'exemple.

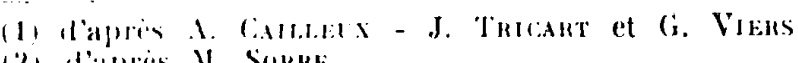

(2) diantis .II. Sinke

(3) d'apres R. Burvet (cf. note 7 ) 
trat camatéristique de lamite correspombante. Wu offet, ééo«systime » met laceent sur le complexe geographique et sur la dymamique diensemble. éeo-« facie » insiste sur l'aspect physio-

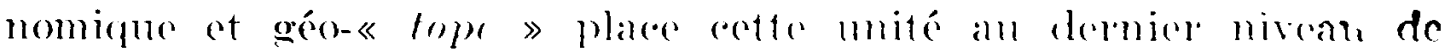
l'échollo spatialo (18).

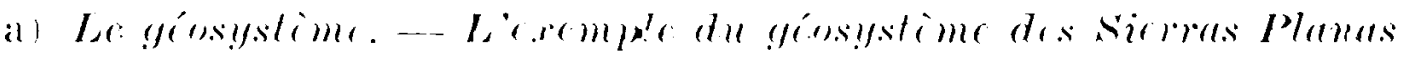

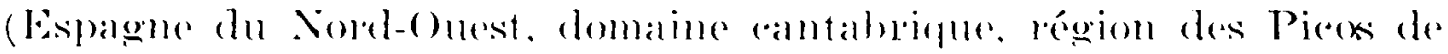

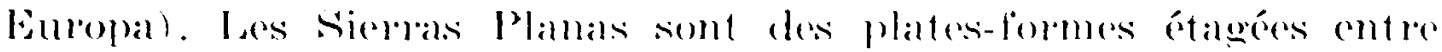

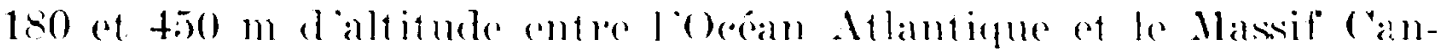

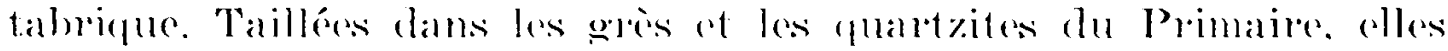

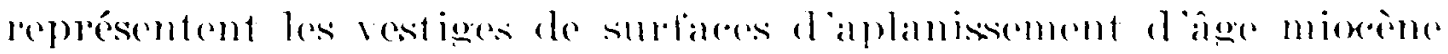

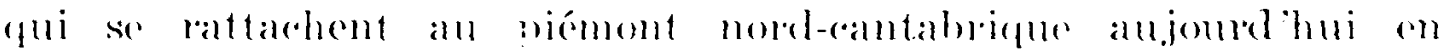

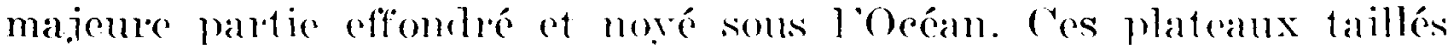

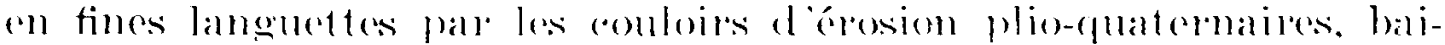

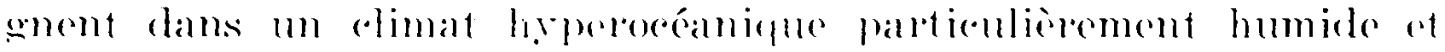

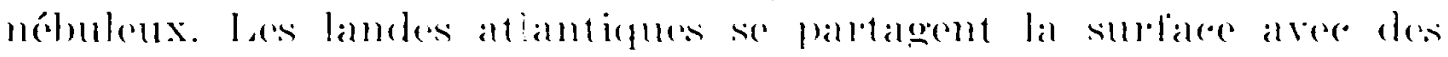

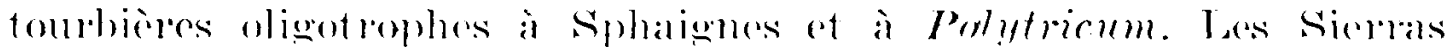

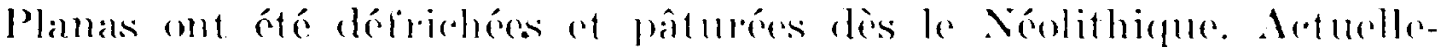

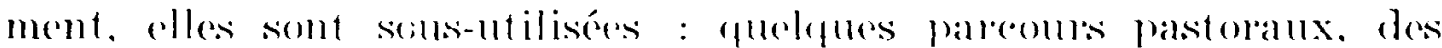

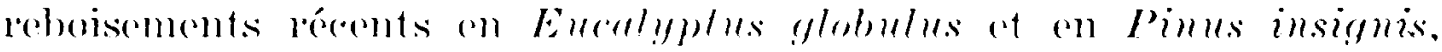

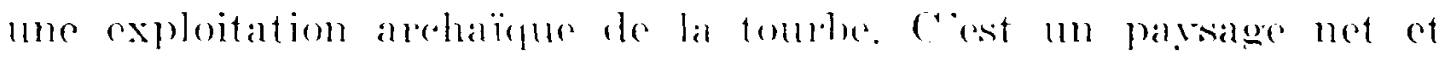
bien circonscrit que lon peut, par axemple. rermer instantanément sur les photographies áriemmes. Poultant les Sierras Planas so

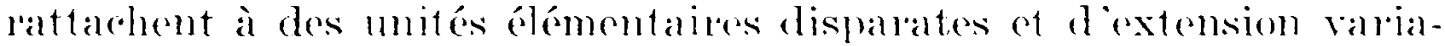
ble : un piemont complexe qui frange tout le rersant norel-eantabrique. un elimat eommun à lensemble du littoral asturien. des phénomenes de podzolisation que lion retroure dans toutes les

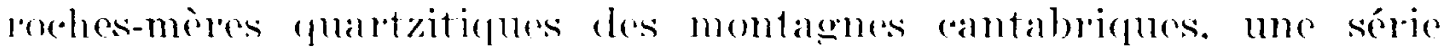

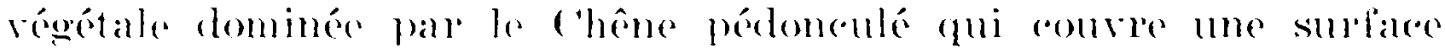

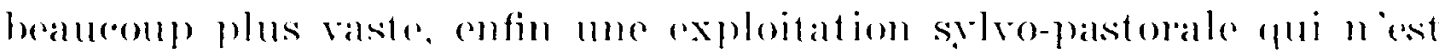

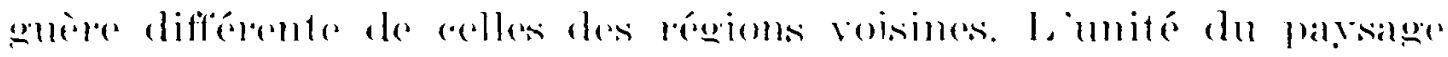
est pourtant incontestahle. Ealles résulte de la rombinaison locale et

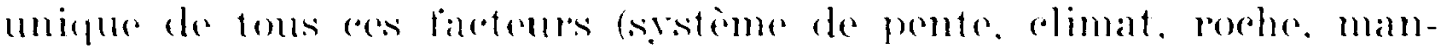

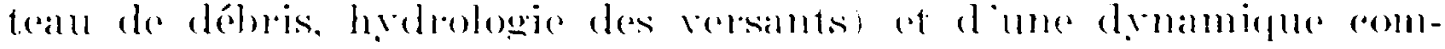

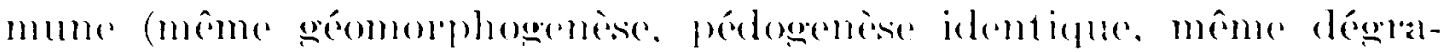
dation anthropigue de la regetation qui aboutit an paralolimax lande-podzol ou a la tourbiere). Le paysalge des Sierras Planas so

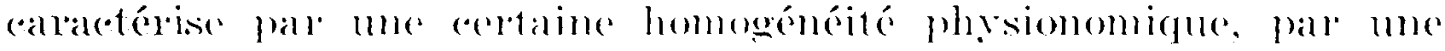

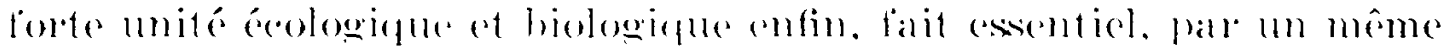

(18) Dans une premiere slusk consacres a l'analyse d'un cals concret (G. Bl:k-

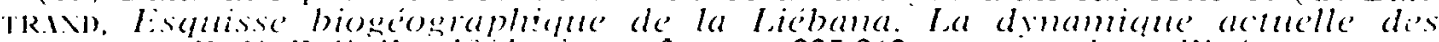

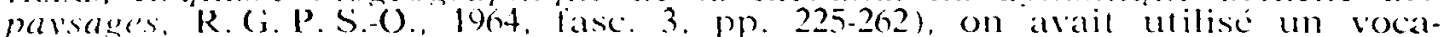
bulaire diflerent qui allat ete criligue par un certain nombre de spécialistes. 
type dérolution. Cot exemple permet d'espuisser nue définition théorique du géoststems (lï. 1 ).

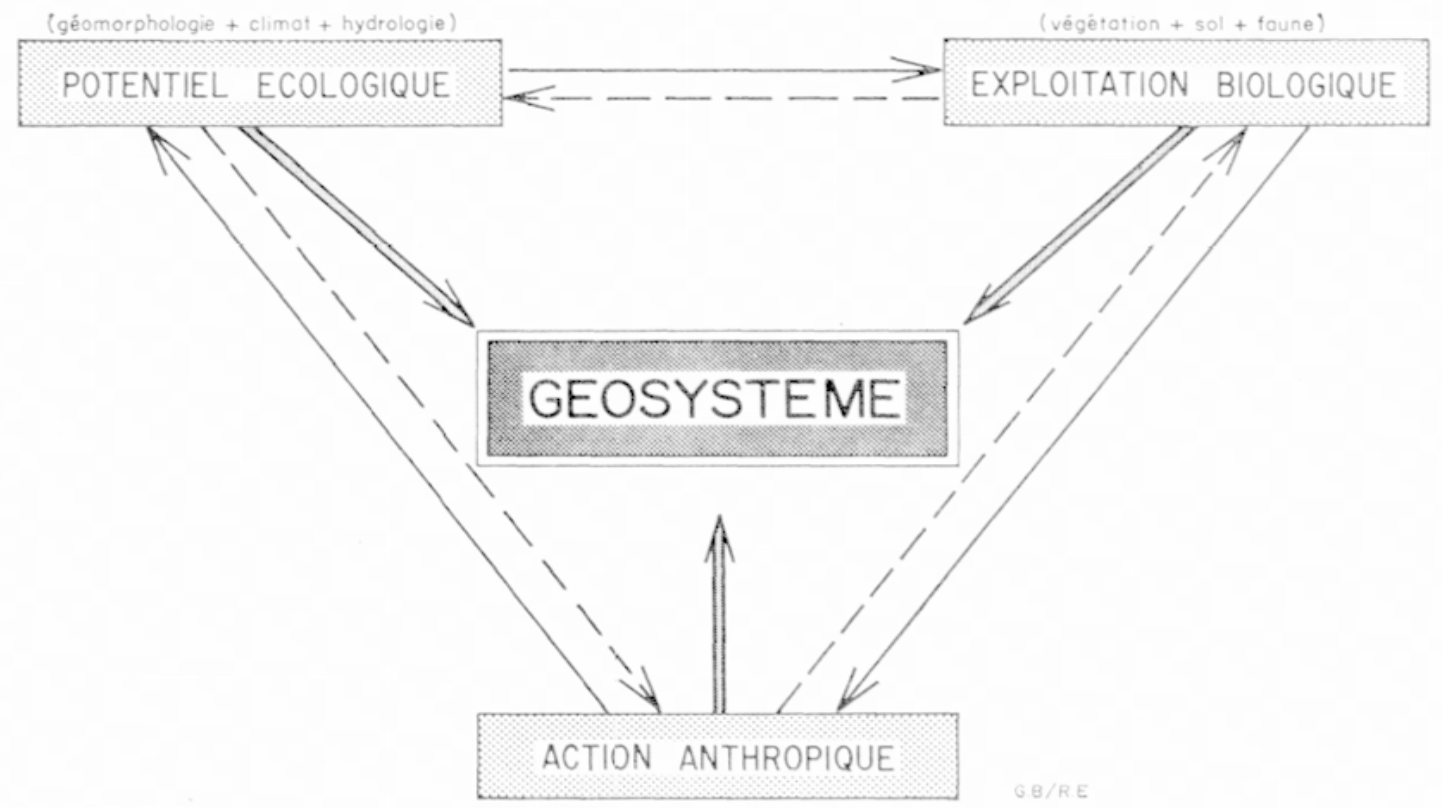

Le gésystime se situe cuthe la quetriems ot la cinequiome gronde ur tomporo-spatiale. Il sareit donc d'ume mité dimensionmelle amprise entre quelques kilometres calrés ef quelques centaines de kilomètres carlés. ('est à cotte échelle que se placent la plupart des phé-

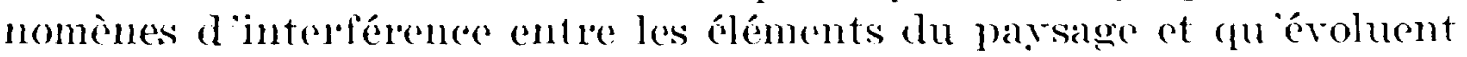
les combinaisons dialectiques les plus intéressantes pour le géowraphe. A un nivoau supérient, souls importent le relief et le colimat et, alcessoirement, les grandes masses régétales. A m niveau in tórieur. les éléments biogéogmaphiques risquent de masquer les eomhinalsons d'onsemble. Eufin, le gésestème eonst ifue une bomme base

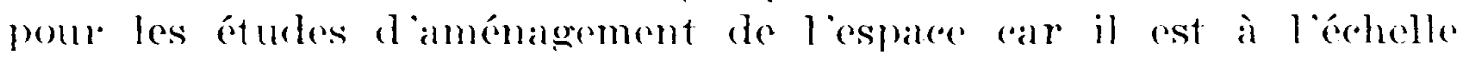
do l homme.

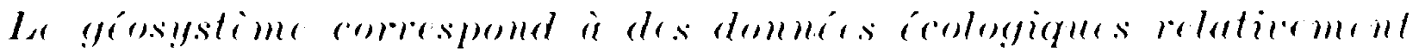

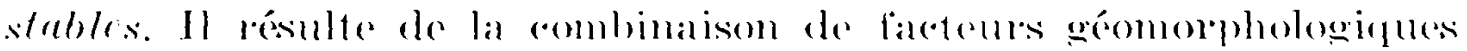
(nature des roches al des manteaux superficiols, valeur de la pente.

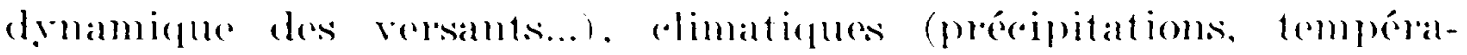
ture...) at hydrologigues mappes phreatiques epidermiques et

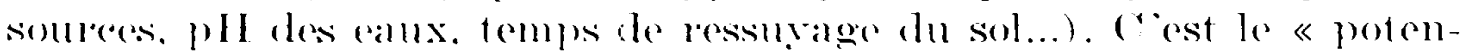
tiel écologique » du géostisteme. Il est ítudié pour lui-même of non sous lasperel limite diun simple « envirommemont ». Pour une soul-

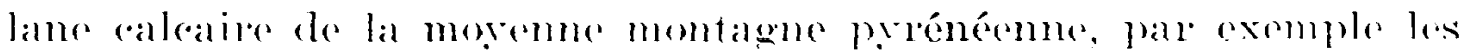

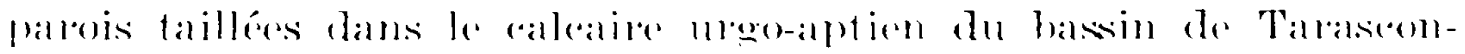

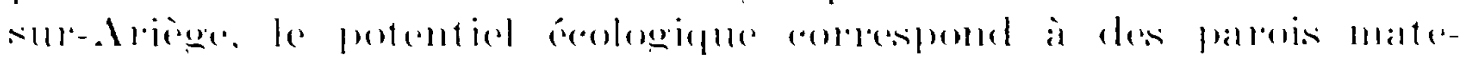




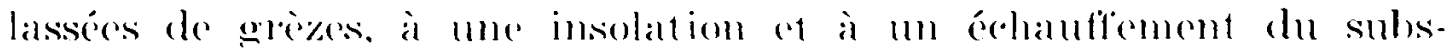
tratum supérieurs à la moxenne régionale. enfin à labsenee de

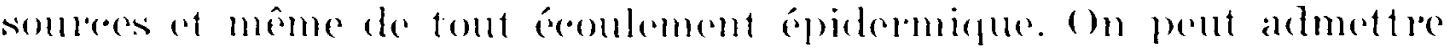
qüil existe à l’échelle ronsidérée, une solte de « eontimmum »

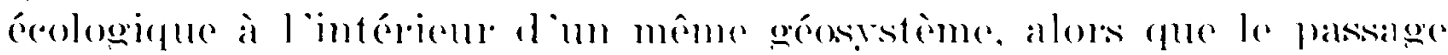

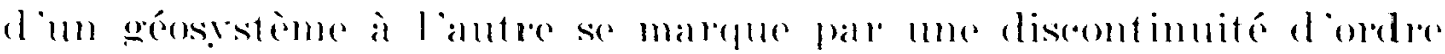
irologinue.

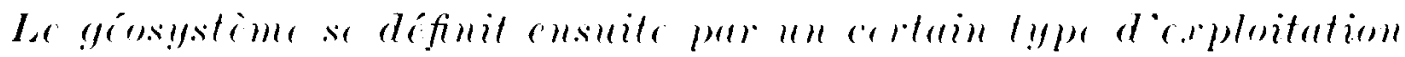

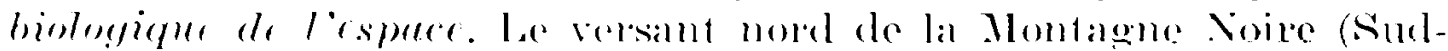

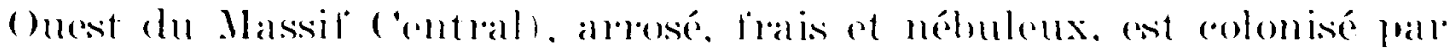

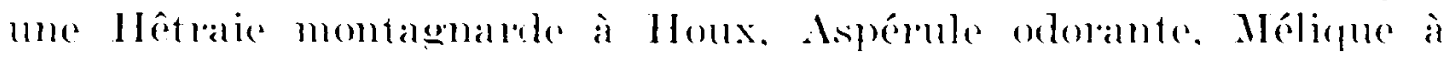

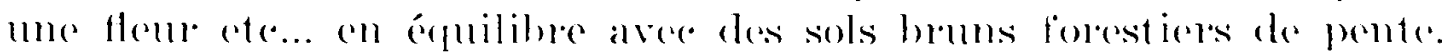

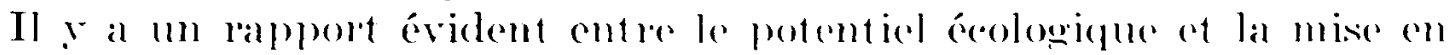

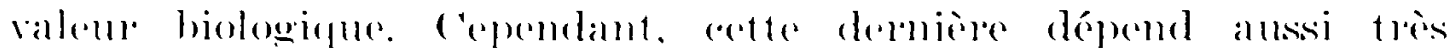
étroitement du stoek fleristigue régional. Pal exemples si le Salpin

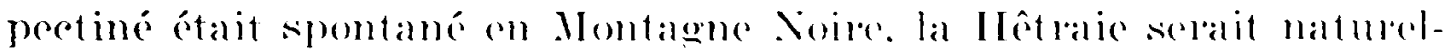

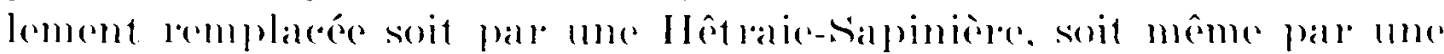
Sapinierer pure à Promenthes purpured stur sols lessivés oll stll sols pentrolicunes.

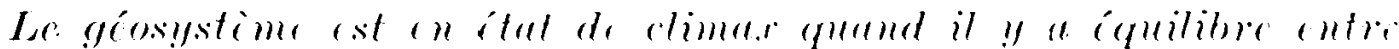

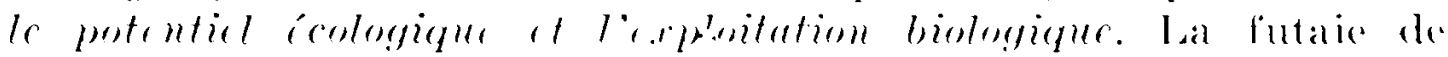

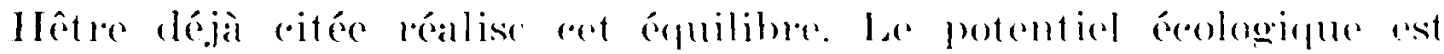

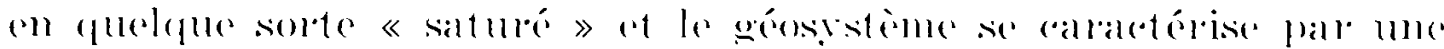

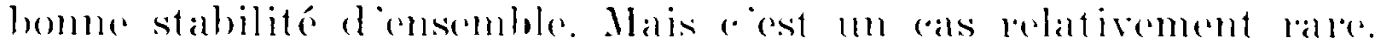

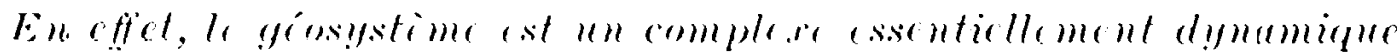

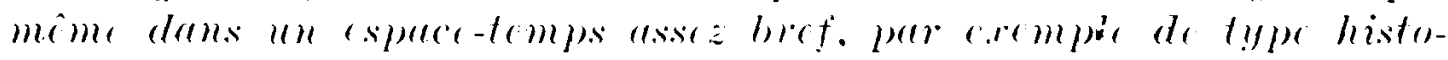

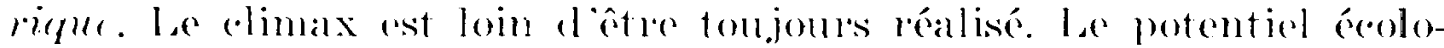

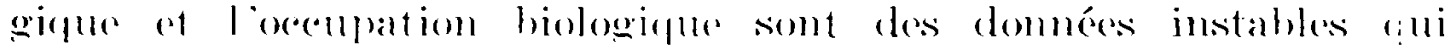

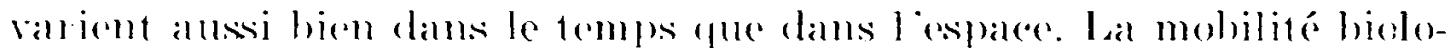
gique est bion romme dymamique naturelle de la vépétation at des

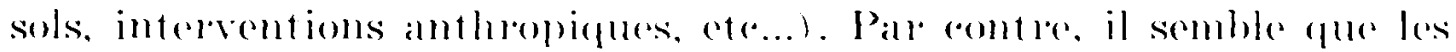

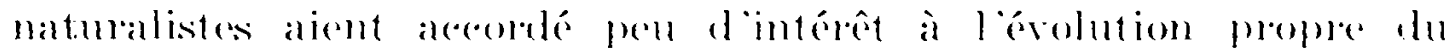

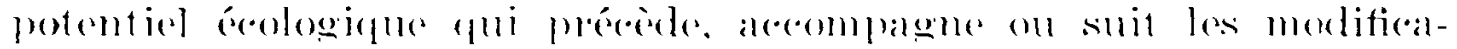
tions dondere biologigue. Par exemple. la destruetion dime foret

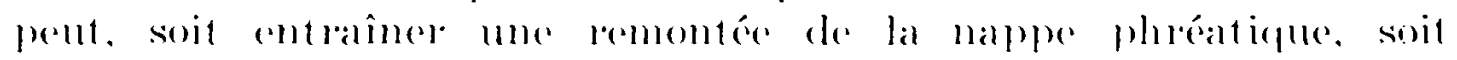

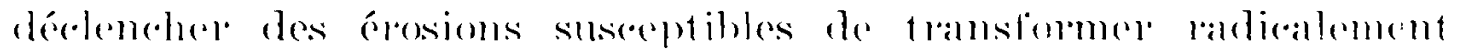
les comditioms écologigules. las notions de « falctentr-limitant » of de «mohilité écologique » méritent $u$ examen approfondi de la part

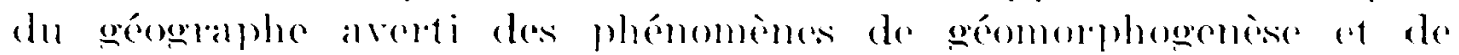
dégalation anthropique (19).

(19) Sur la notion de " mobilite coologique", of. G. Brirtraxb, Ponr une cilude géosraphique de la légétation. R. G. P. S.-O., 1966, fasc. 2, pp. 129-143. 


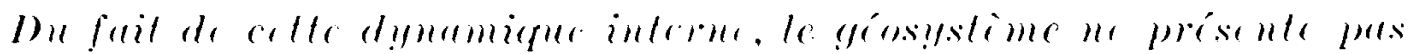

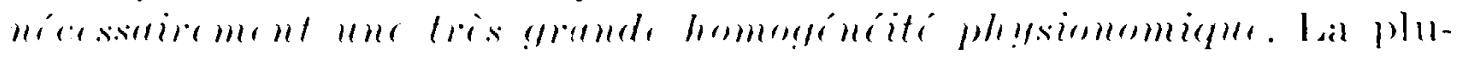

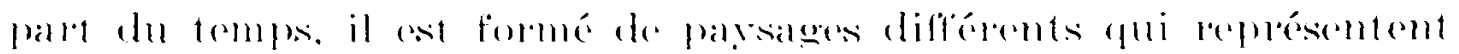

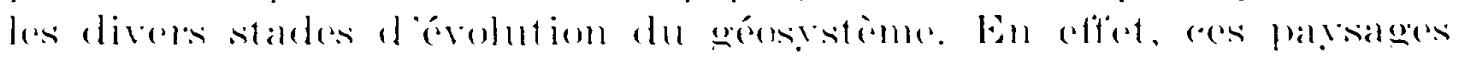

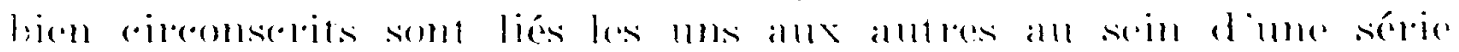

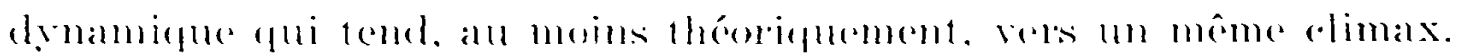
ces unités phesiomomiglues se rattareheme done à une même fimblle séographicpue. ('o somt les quétaciès » pl. vir $A$ et $B$ ).

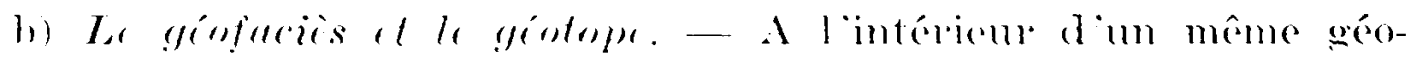

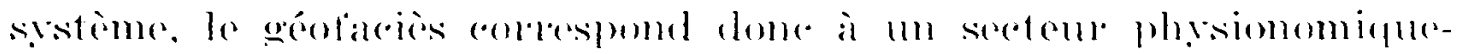

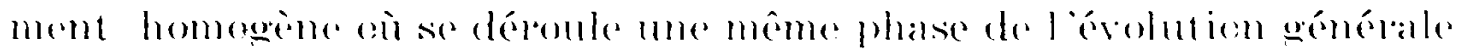

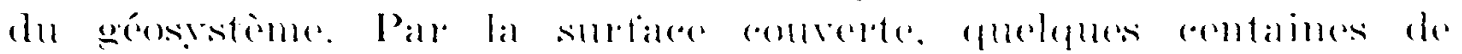

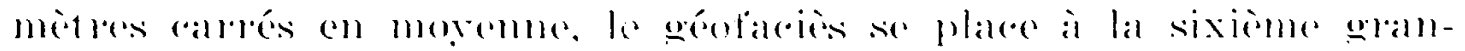

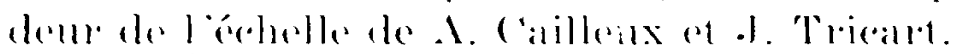

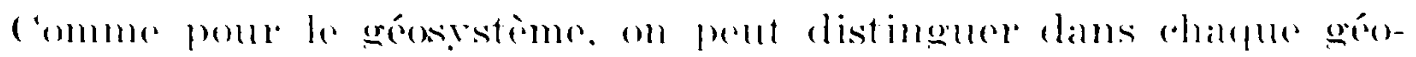

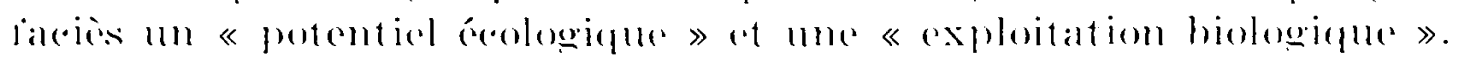

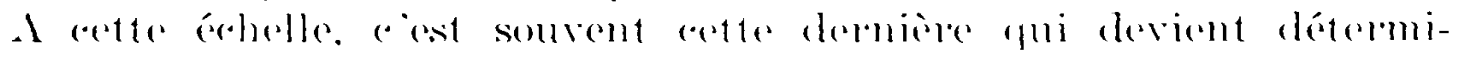

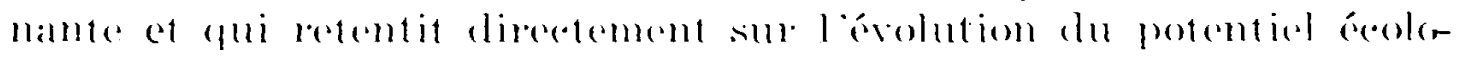

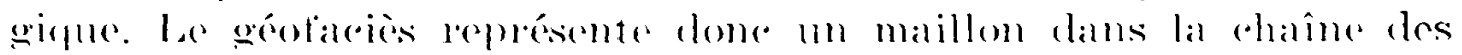

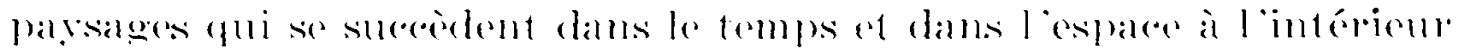

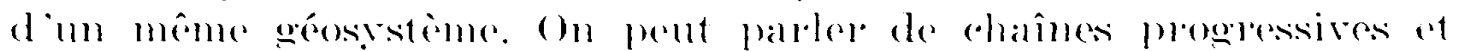

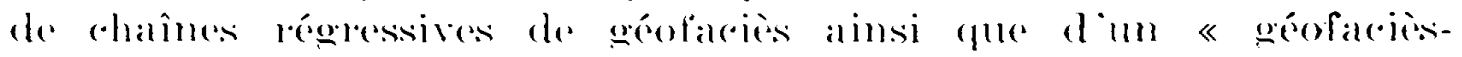
elimax $\gg$ qui eonstitue le starle final de lévolution naturelle du géo-

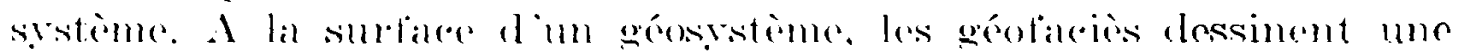

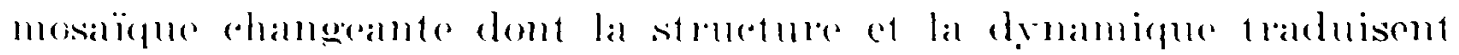

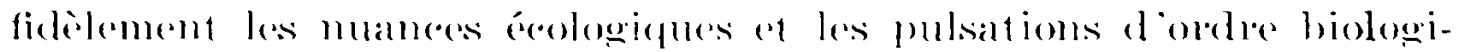

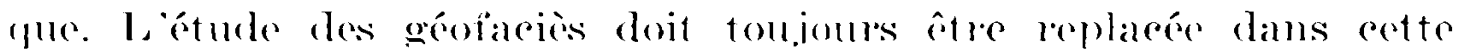

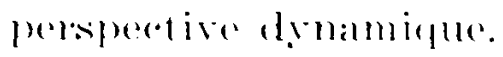

Il est partois indispensable de eonduire lamalyse an nivanu des

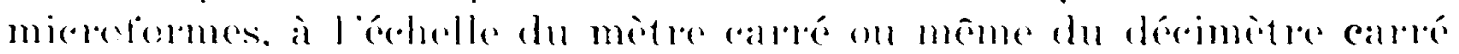

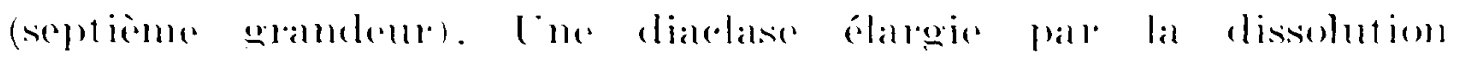

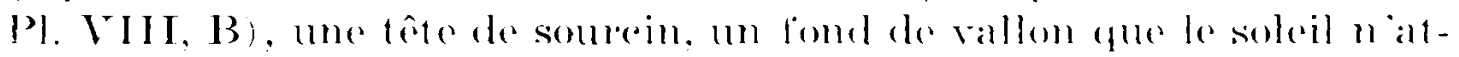
trint jamais, une viere montagnense, eomstituent antant de biotopes

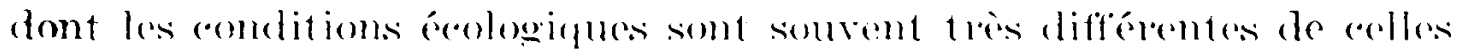

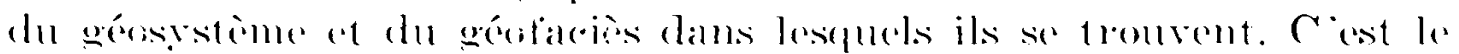

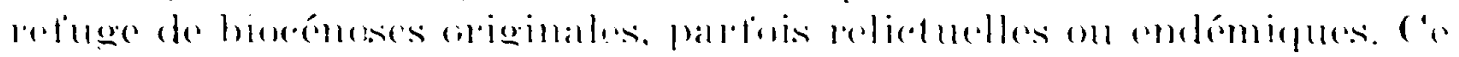

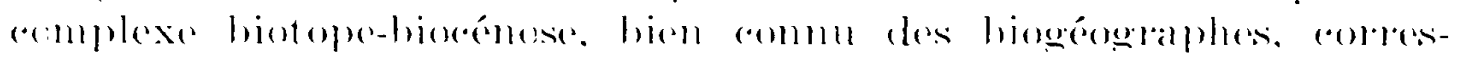

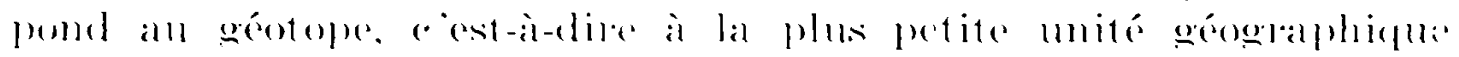

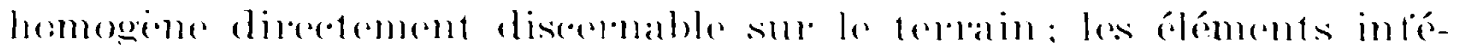

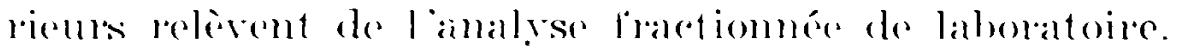

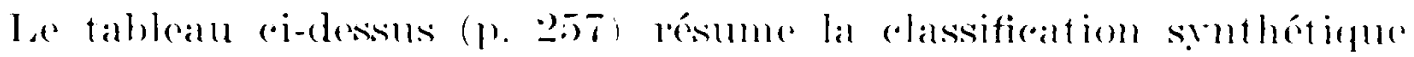

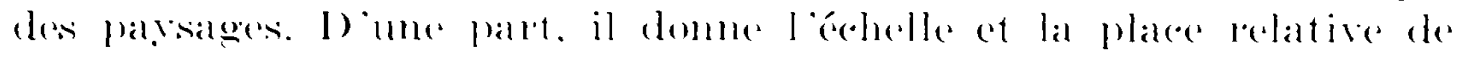




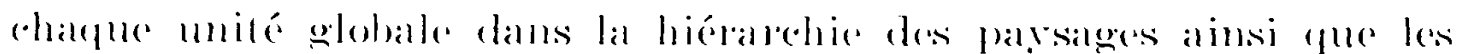

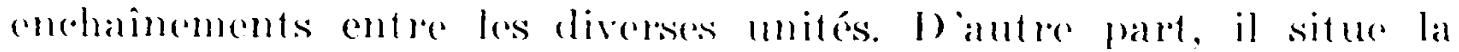

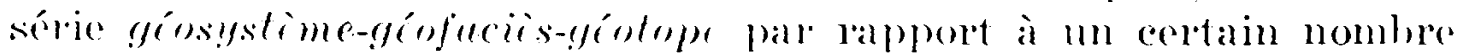
d immités ot de classification élómentaires.

\section{La dynamique du paysage}

En comsidérant le paysalge romme une entité globale. on admet implicitement que les fements qui lo constituent participent à une druamigue eommune qui ne colrespond pas obligatoirement a lévolution de chatem dientre ellx pris séparement. On est dome amené à recherehel les mécanismes généralux du parsalge. ch parti-

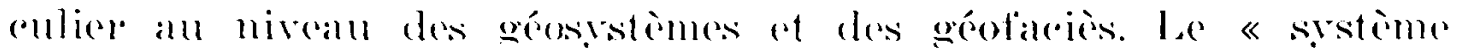

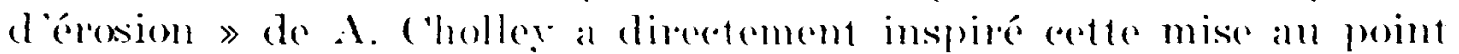

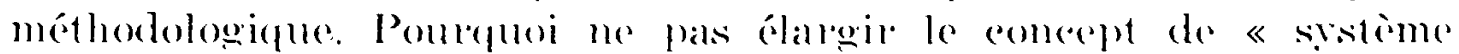

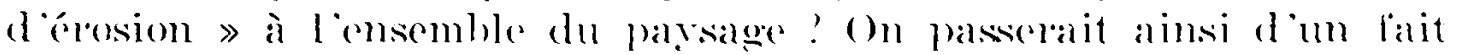
strictement géomomphologrigue a la notion plus vaste, plus complete ef somme toute plus géngraphique, de « sisteme général d'érolution » du parsalac.

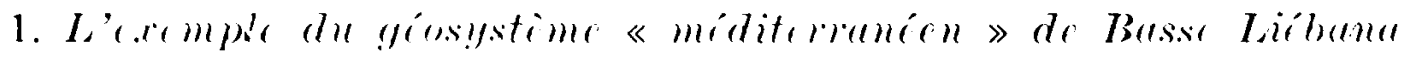

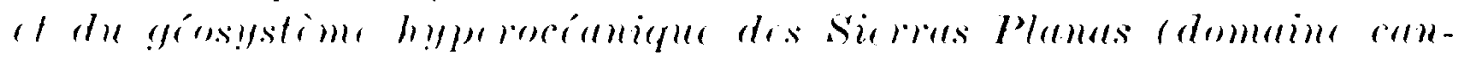

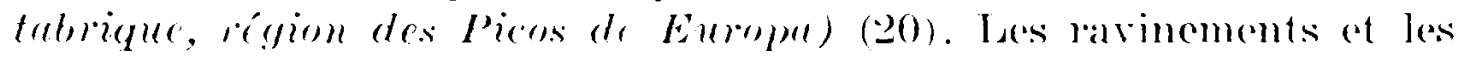
décapages do versants sont liéfuents on Basse liébana. Les aduses sont d abond gémompholngigues (puissante dissoretion plio-guaternaile dans des schistes tendres. manteatux superficiels épats ct instables) et phytogeographiques (tapis régétal clairsemé et fragile de type relictuel, c'est-ì-dire en déséquilibre hioclimatique). lal situation est alewarée par le sisteme de mise en valeur anthropigue qui multiplic les défichements. les incendies et la surpéeoration des forêts claires, des maquis et des garrigues. las sols sont discontinus of mal evolués (types rankeritommes). La weomorphogenese ronditionne done la dronamique densemble de re géosristème et domine le «sisteme d'évolution » du parsage (Pl. vir $\Lambda$ ). sur les Sielras Planas. les pasteurs asturiens ont détruit la forêt pour étendre les surtaces enherbées. Ils ont décelenché une cascade de processus pédologiques fondzolisation, tomphification of hydromorphisation). botanigues (extonsion des lamdes ateidifiantes) ot parfois même geomonphologigues (mise on molvement des manteanx sableux déjà pédogénisés). la pédogenèse joue jei le rôle essentiel

(20) G. Birtrivi), ibial note 18, pp. 236-248. 


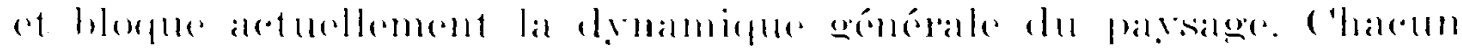

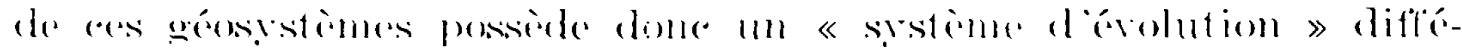
int.

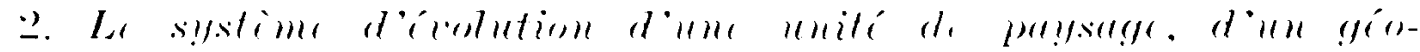

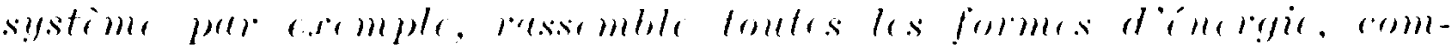

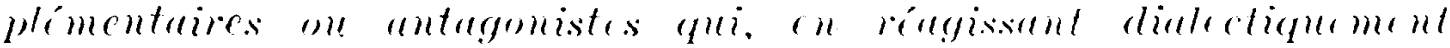

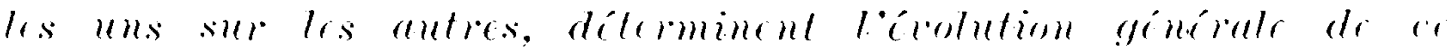
paysuge. Pour les hesoins de lamalyse, on pellt isolep trois ent-

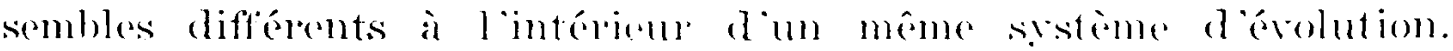
En lait, ils sont étroitement solidaires of se recoupent latrement :

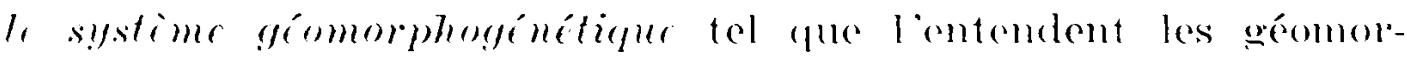
phologues modernes qui insistont sur som allatetion « drollamique 》 (4) « hoclimatique » (.I. Trioant) ;

la d!mmemique biologique qui intervient an nivoan du tapis vé-

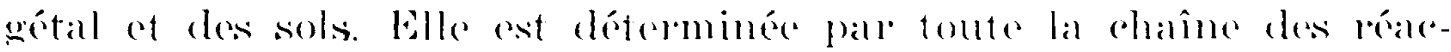
tions écophrsiologigues qui se mantestent pall les phenomenes dadaptation (écotypesi), de plastieité, de disséminationt. de conemr-

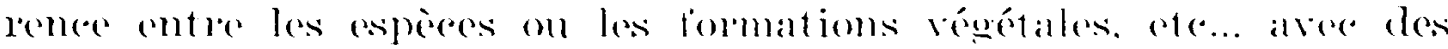
prolongements all niveau des sols.

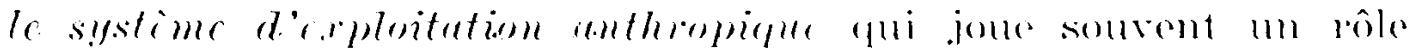
déterminant, soit en activant on en déclenchant des érosions, soit

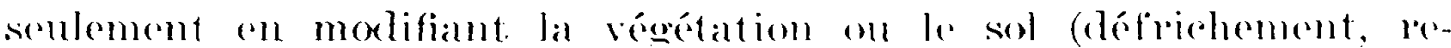
boisement...).

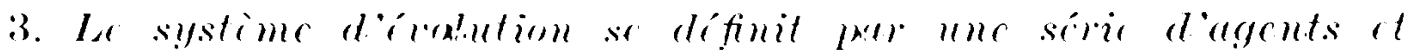

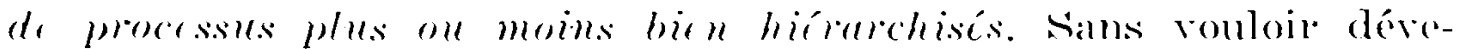
lopper iei oette question. on pout distinguer des agents naturels (climatiques, hologiques. ete...) qui déterminent des pooessus na.

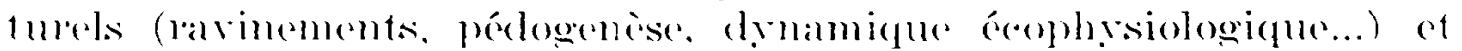
des agents anthropiques (sociétés aglo-pastorales, forestiers...) dont

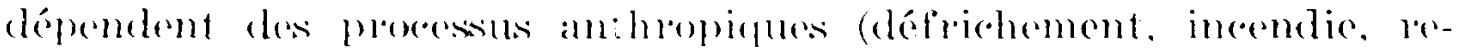

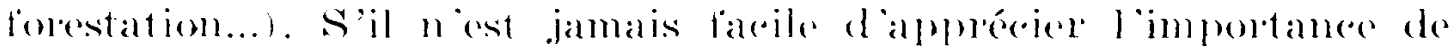
tel agent on de tel processus isole, il est erpendant possible de chasser les systemes dérolution en fonction du ou des factems

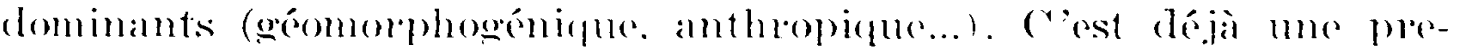

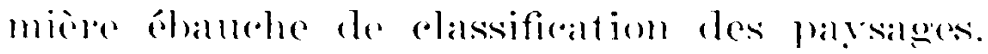

\section{La typologie des paysages}

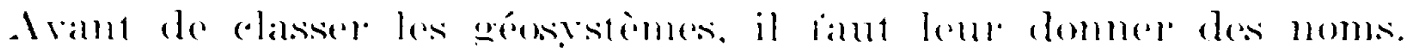
Il sagit de defonir le plus brienement possible des rombinatisons 

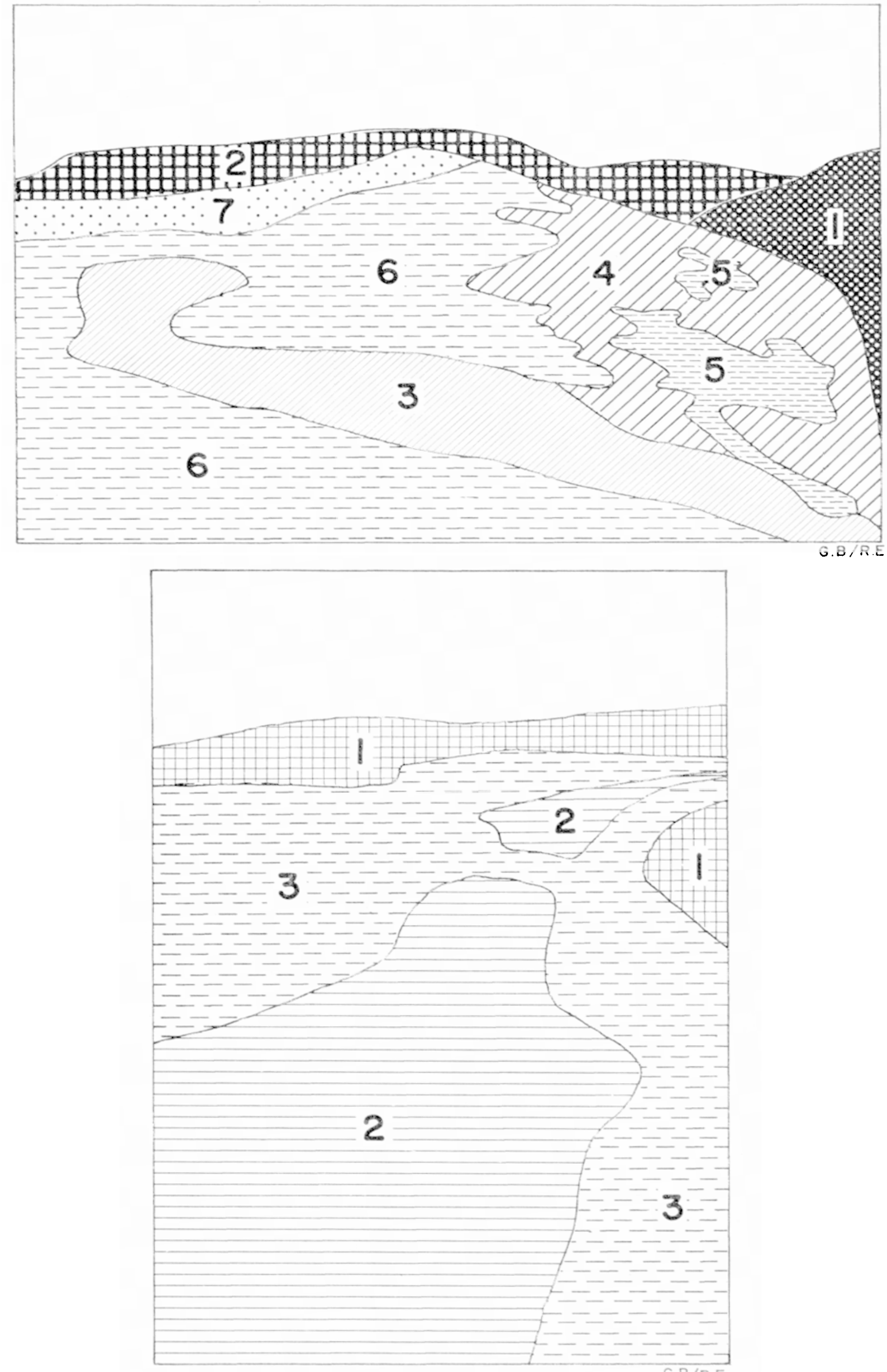

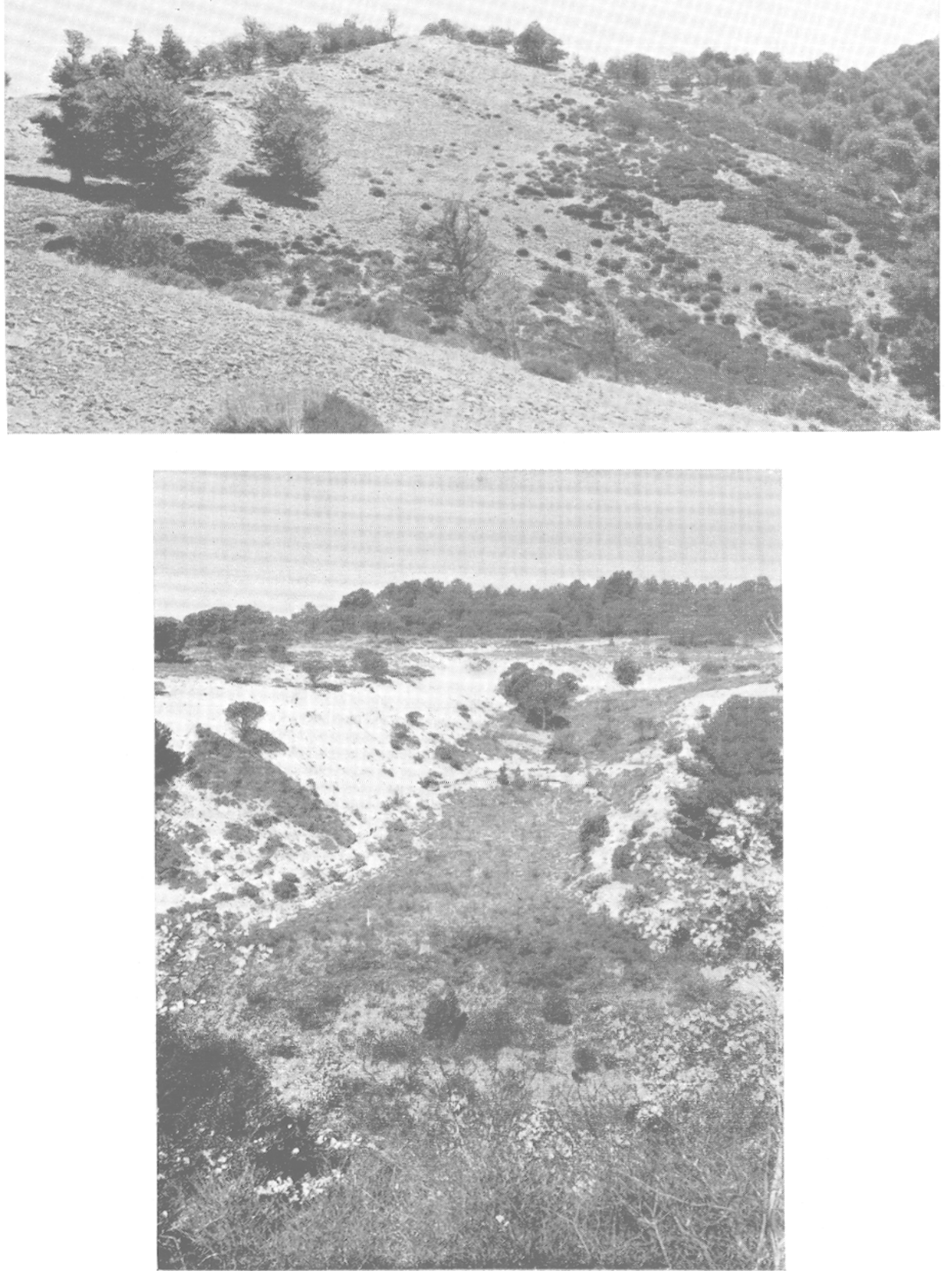

G. Bertrand. - Paysage et géographie physique globale.

Pl. VII, A et schéma ci-contre

Géosystème montagnard-continental " acidiphile" du versant sud cantabrique (col del Pando, $1400 \mathrm{~m}$ d'altitude, valle de Prioro).

1. - Géofaciès assez stable et peu éloigné du climax. Versant schisteux entièrement couvert par un manteau de plaquettes de schistes en cours et Anémone Sylvie sur chaîne de sols bruns forestiers à Moder.

2. - Géofaciès de la Hêtraie-parc régulièrement pâturée à Hellébore fétide (D. lutea $L$.) sur sols bruns minces et tassés.

3. - Géofaciès des fonds de talweg remblayés par des débris fins et des sols bruns allogènes. Lande arborée à Sarotha
Fougere-aigle et Allouchier (Aria nivea Grantz).

4. - Géofaciès de la lande acidiphile à coussinets de Bruyère (Erica
arborea $L$. et aragonensis $W k$ ) et de Sarothamne ( $S$. cantabricus $W k$ ) sur arborea $L$. et aragonensis $W k$ ) et de Sarothamne ( $S$. cantabricus $W k$ sur
sols bruns discontinus et Rankers d'érosion. Plaques décapées par l'érosion épidermique.

5. - Géofaciès des formations ouvertes à Labiées (Thymus mastichina L.) ur régolite instable.

6. - Géofaciès des versants schisteux décapés et recouverts par un micropavage d'éclats calcaires en transit. Quelques touffes de Thym.

7. - Géofaciès de la corniche calcaire. Roche lapiazée et gélifractée.

Pl. VII, B et schéma ci-contre

Géosystème méditerranéen à Chêne vert des causses du Cabardès et
du Minervois (versant sud de la Montagne Noire, Sud-Ouest du Massif Central).

1. - Géofaciès des plateaux calcaires à garrigue de Chêne Kermès, Buis, Thym commun et Brachypode rameux sur sols rendziniformes (reboisement conisation subspontanée de Pin pignon et Pin d'Alep).

2. Géofaciès des fonds de vallons secs remblayés par des argiles de
décalcification. Végétation dense à Genêt scorpion, Spartier et Badasse décalcification. Végétation dense ${ }^{a}$ (Dorycnium suffruticosum Villars). 3. - Géofaciès des versants érodés et instables à " couverture vivante "
détruite : lithosols calcaires, touffes de Thym, Buis et Romarin. 


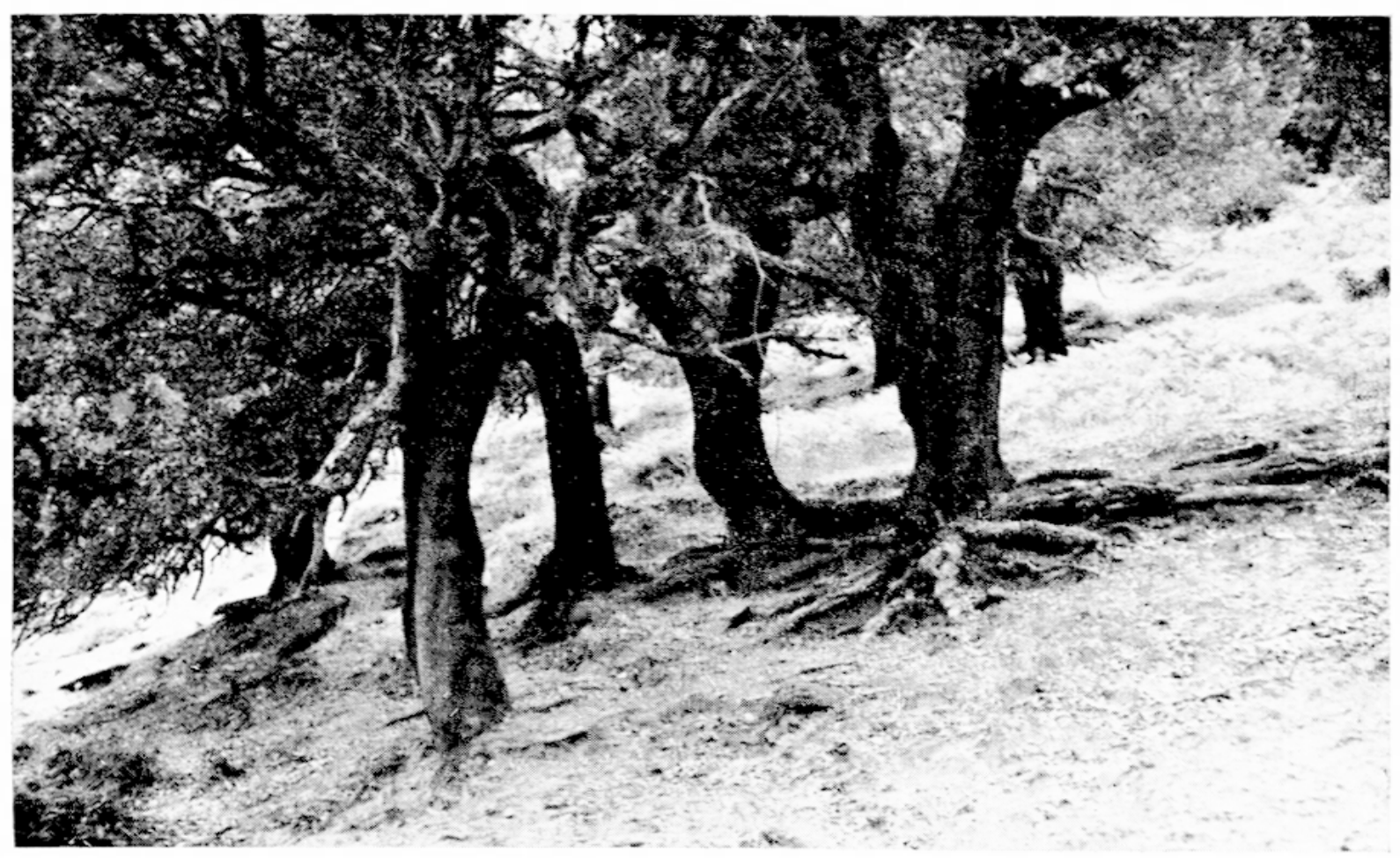

Pl. VIII : A. - Géosystème méditerranéen " acidiphile " de Liébana (Picos de Europa, versant nord cantabrique, $400 \mathrm{~m}$ d'altitude).

Au premier plan, Subéraie claire soumise à l'érosion épidermique. Les sols bruns climaciques ont été décapés et les racines dénudées. Régolite mobile et litière non décomposée. Au deuxième plan, lande à Fougère-aigle et Cistes à feuilles de Sauge sur des sols bruns tassés.

B. - Géotope à Aspidizm Lonchitis Su'. sur "auto-sol " humique carbonaté logé dans une vasque de clissolution karstique du calcaire viséen (géosvstème montagnard-atlantique de la Hëtraie calcicole, Picos de Europa, $1400 \mathrm{~m}$ d'altitude). Dimensions de la carité : $30 \times 60 \mathrm{~cm}$.

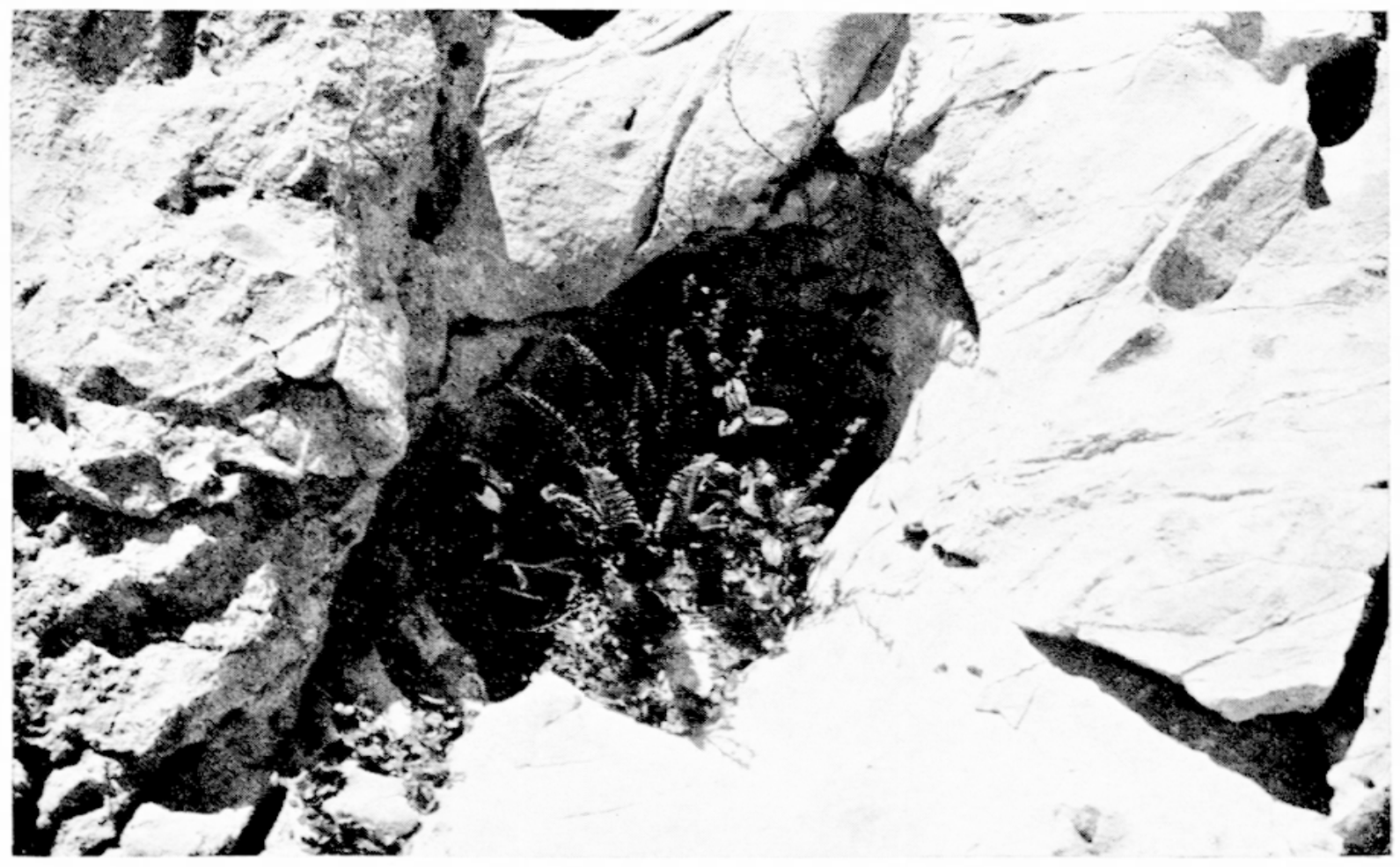




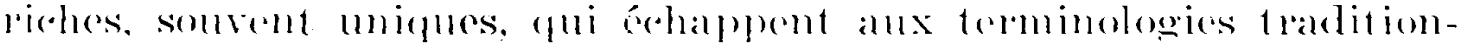

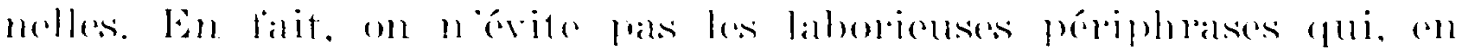

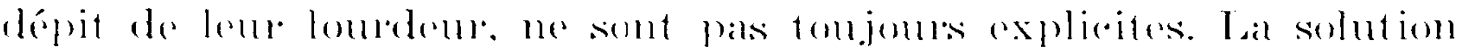

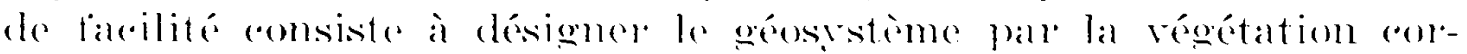

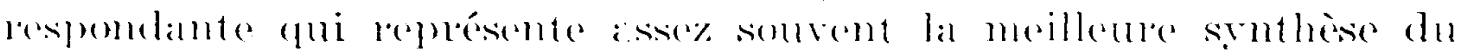

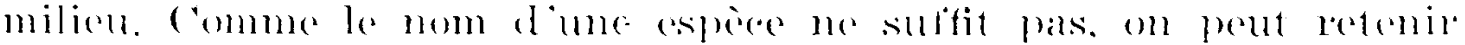

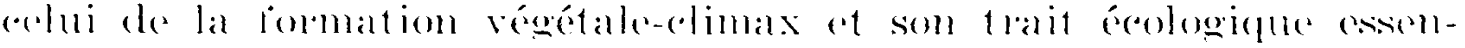

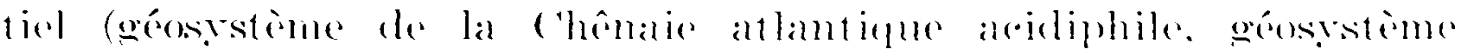

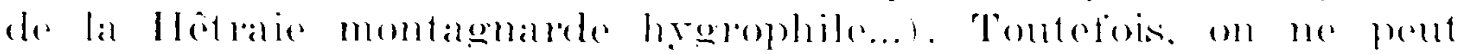

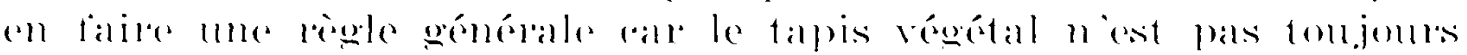

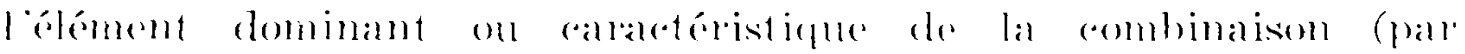

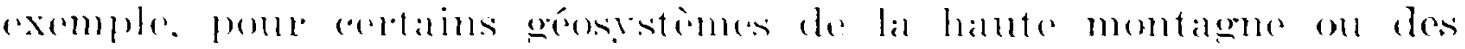

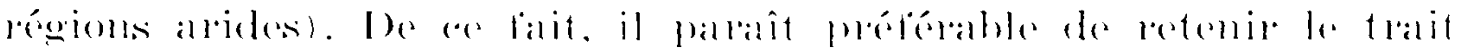

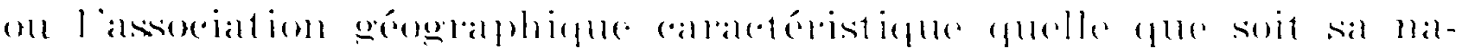

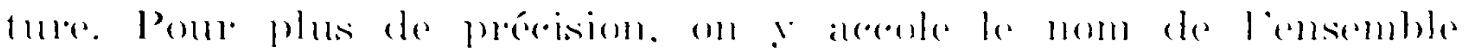

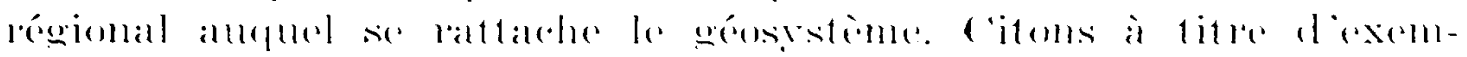

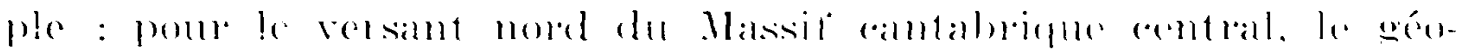

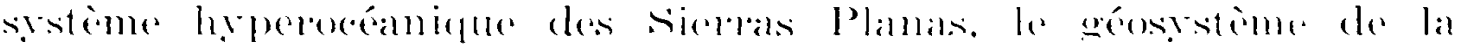

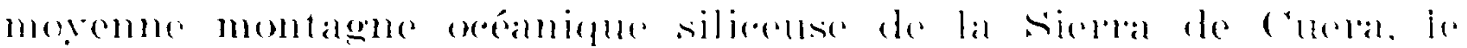

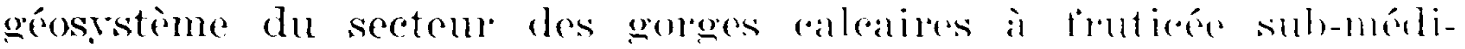

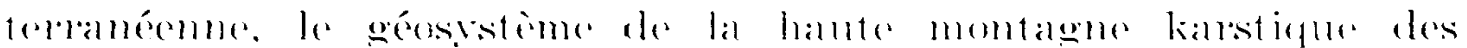

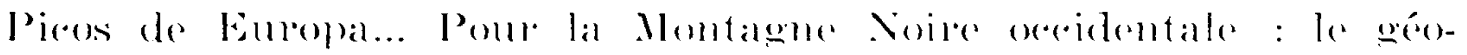

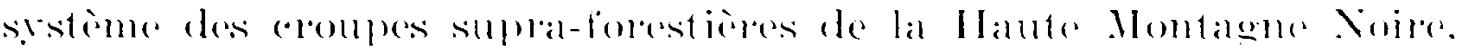

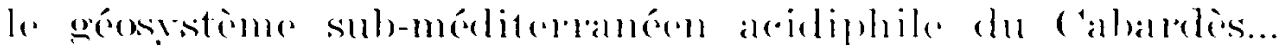

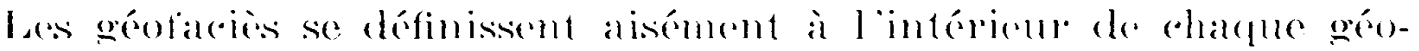

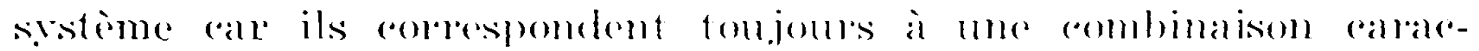

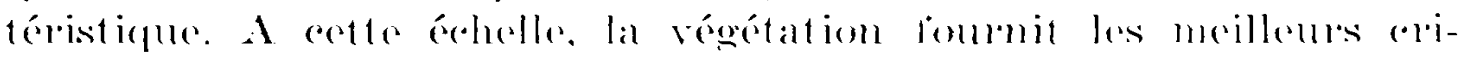
teres, on particulier sous la forme des proupements phytosociolo-

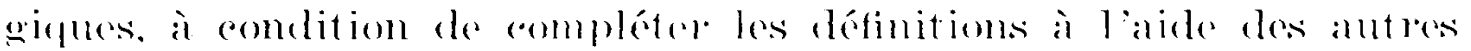

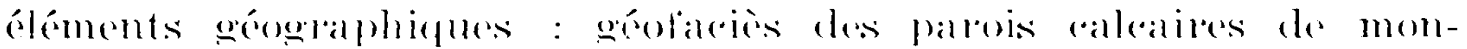

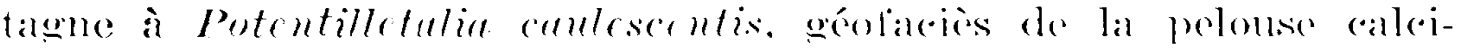

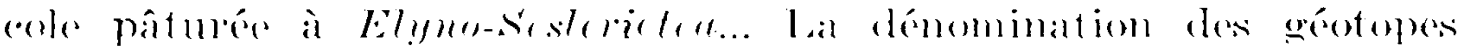

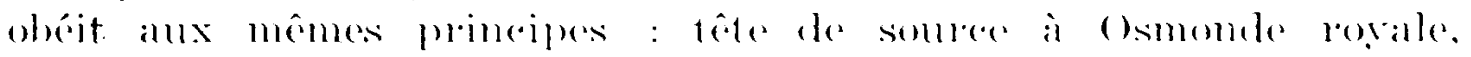

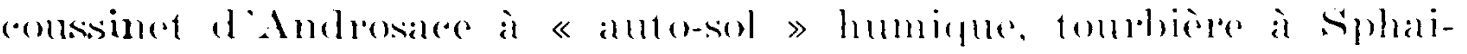
gnes...

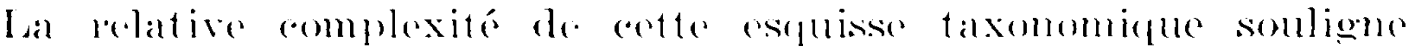
partaitement les problemes que pose la rassification globale des

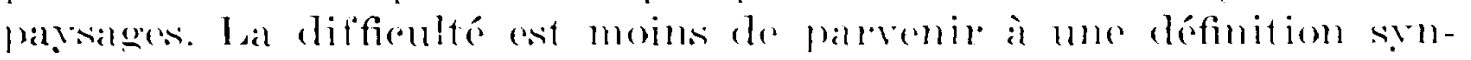

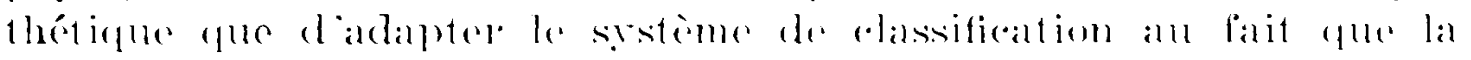

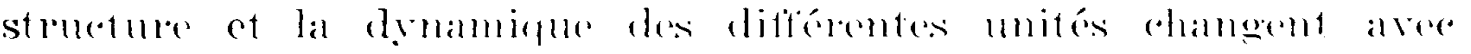
l'arledle.

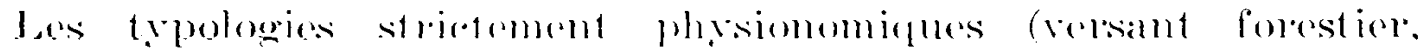

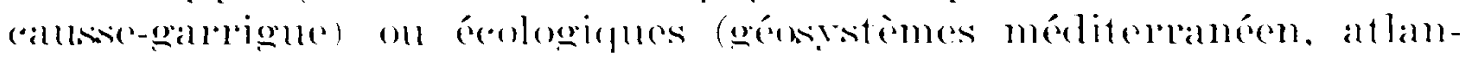
tique. montagnard...) nont pas domé les résultats escomptés. Elles 


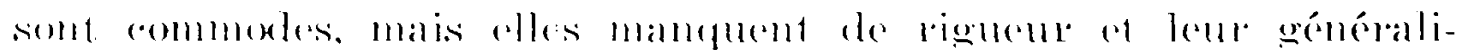
salion est difficile. Ie choix s'est porté sur une lypolengie dyme-

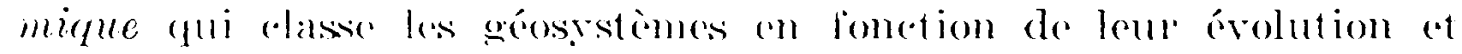
qui englobe de re fait tous les asperets des parsages. Fillo tient compte de trois éméments : du systeme dévolution, du stade atteint par lapport an elimax, du sens général do la dyomigue (poro-

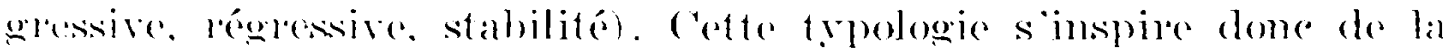
thérie de hiomexistasie do II. Erhant. On a distingué sept types de géosistemes regloupés on denx ensembles dyamiques différents.

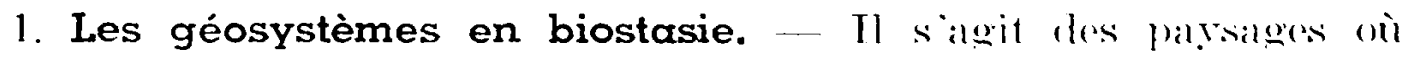

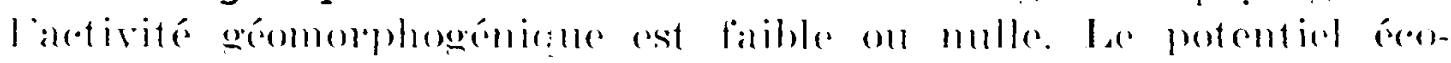

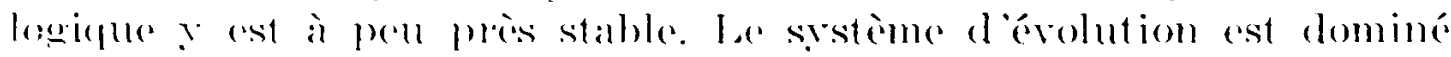

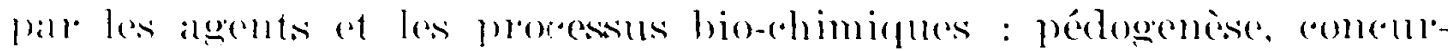

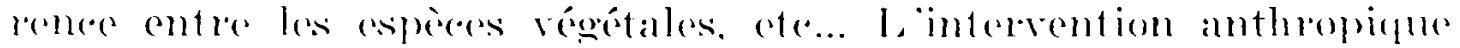
pent entrâner umo dynamigue régessive de la regétation of des

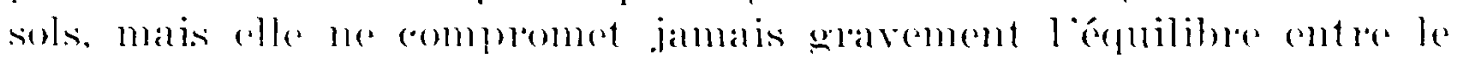
potentiel écologique of lexploitation hiologigue. ('es géosytemes

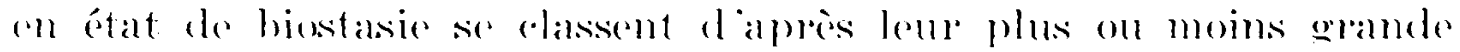
stabilité.

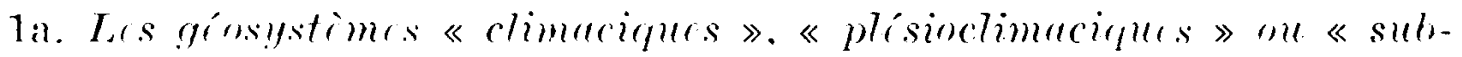

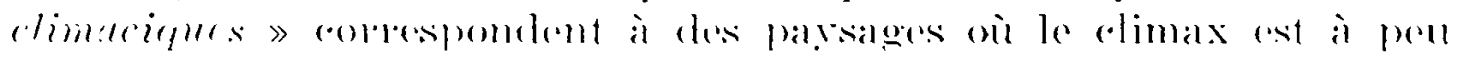

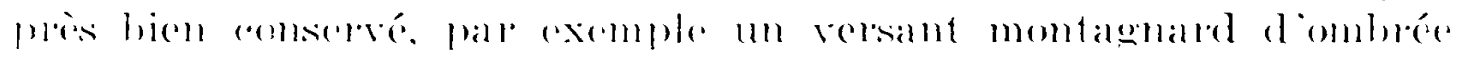

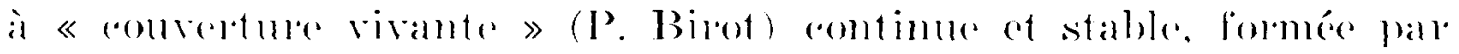
me fulate de lôtres sur des sols brums forestiers a Mull-Moder. l. intervention humaine, de caratelere limite, ne compromet pas

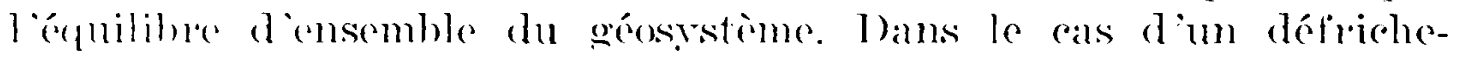
ment ou meme d'un aceident « natuled » (coulée boueuse), on assiste asso\% rapidement à une reconstitution du eouvert régétal ot des sols: le potentice écologeigue ne paraît pas modifié.

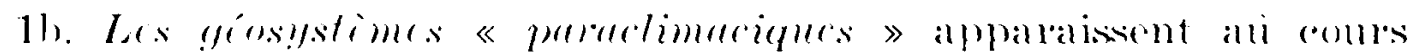
deme écolution régressive, généralement dorigine anthropique. lorsefue sopreve un blocage relativement long lié à une modification

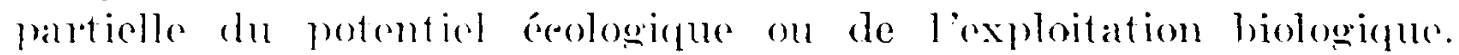
te meillem exemple est relui du áeststeme hyperocéanique des

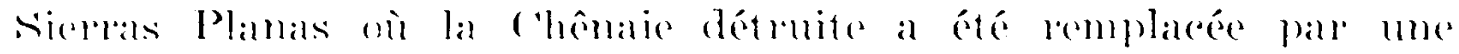

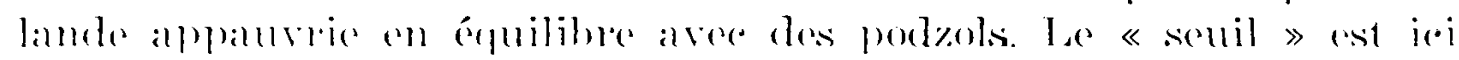

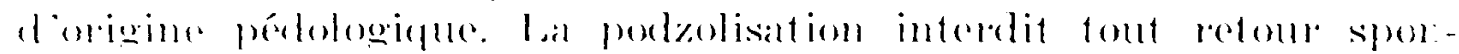

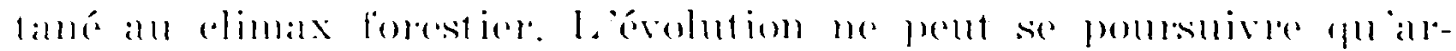

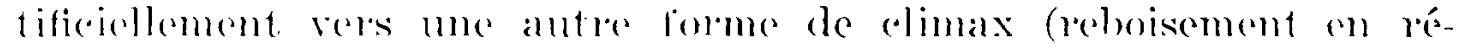
simenx apres sous-solalg(e). 


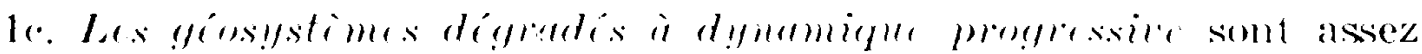

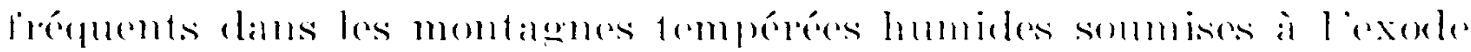

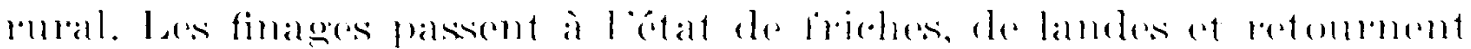
a $u n$ éal forestier qui est la plupart du tempse different de la

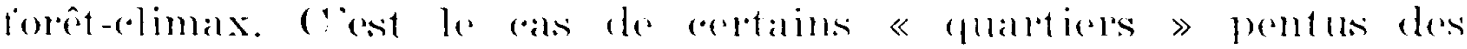

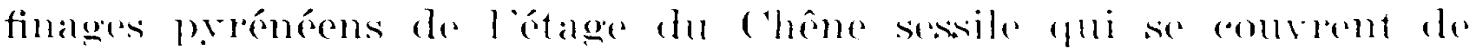
taillis a Noisotiers. Bomleanx. Chataigniels et chênes divels qui ne

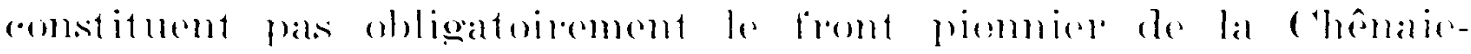
elimax antérienuement détruite.

11. Las giosystimes dégrodés ì dymumique régressive sures mo-

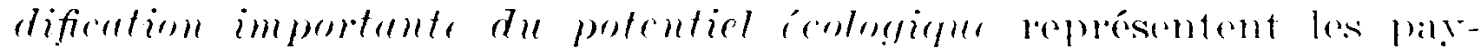

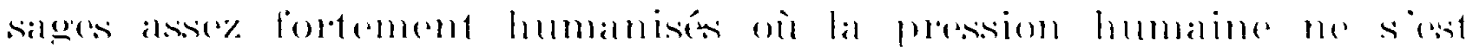

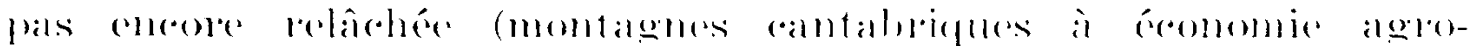

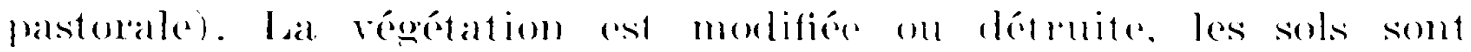
tramstormes par les pratiques rulturales et le pareoulds des ami-

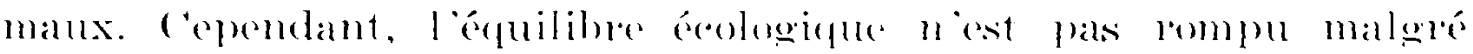

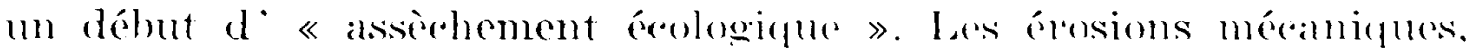

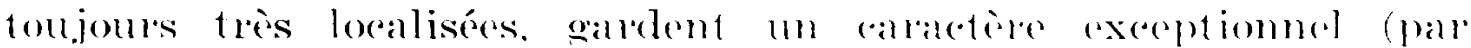
cxemple k lone des diailless).

2. Les géosystèmes en rhexistasie. La gémorphogencise do-

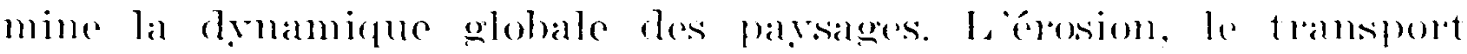

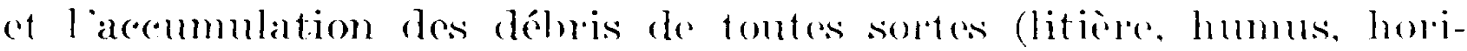
zons pédologigues, manteaux superficiels ef fragments de roche an place) entrainent uno mothilité des rersants et nue modification phus ou moins poussée du potentiel écologique. Ia géomorphogenesse contrarie la pédogenése et la colonisation régétale. Copendant, il faut distinguer deux niveaux d'intensité :

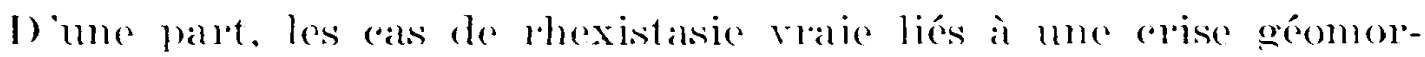
phoclimatique capahle de modifier le medele et le relieft. Ide systeme dérolution des paysares so réduit alors an sisteme dérosion classique. La destruction de la végetation ot du sol peut dans ee

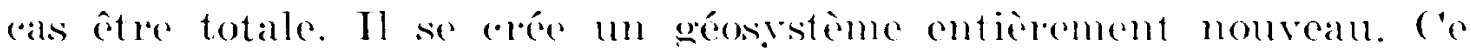
phénomène est frépuent sur les mareses des régions arides où il est sourent arecolere par l'exploitation anthropique (« mauraises

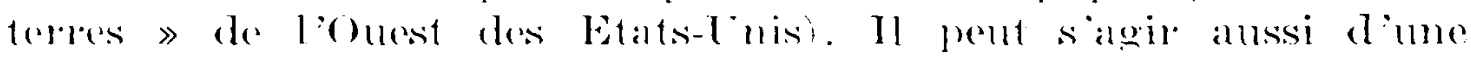
rupture déquilibe « ratastrophique » (par exemple lave torrenticlle en montagne).

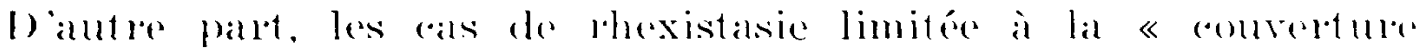

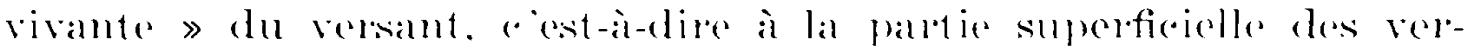

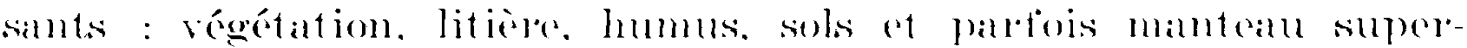
ficiel et nappes phréatiques épidermiques. Cotte erolution na pas encore sulfisimment interessé les geographes of les hiogéographes. 


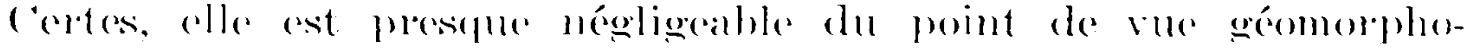

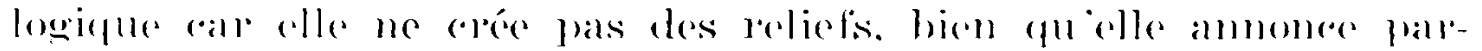

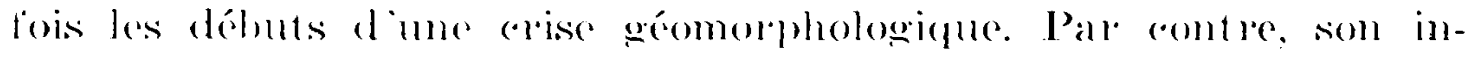

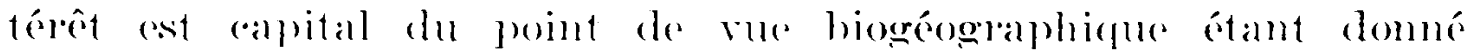
quidle mobilise toute la frange hiologiquement artive du versant.

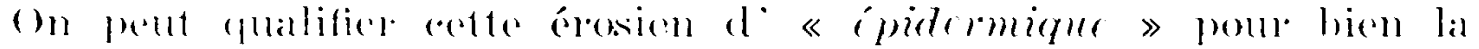
distinguer de lóression réritable on « gémomphologique » et afin deviter les confusions et les discousions inutiles qui ont pendant un eertain fomps opposé les tenants of les adversaires de lérosiom

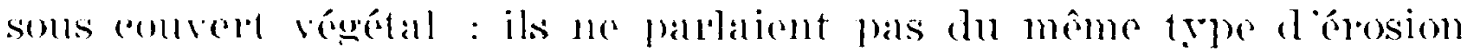
ni du môme courert régétal ef no se placaiont pas à la même

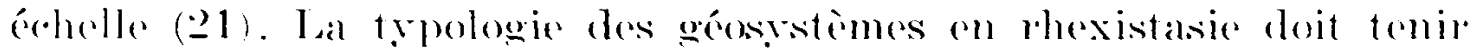
(eomple de toms aes latits.

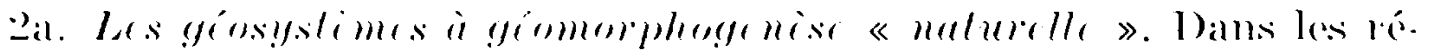

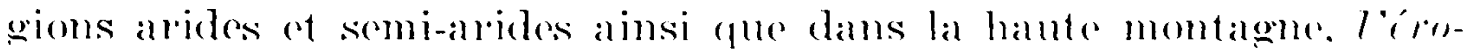

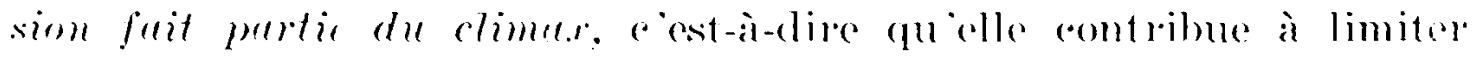
naturellement le dereloppement de la répétation et des sols (rep-

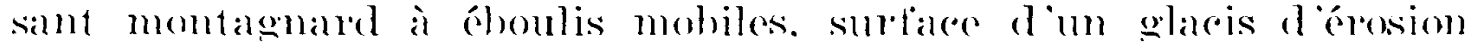
entreatemu pall des épandalges dimed).

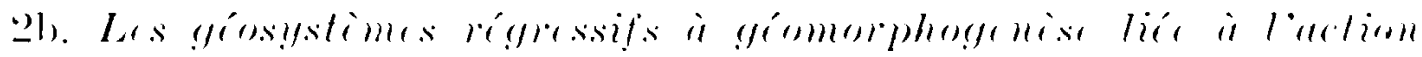

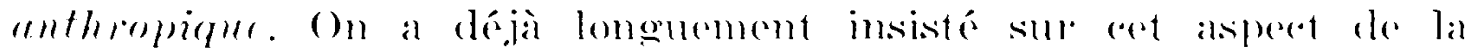

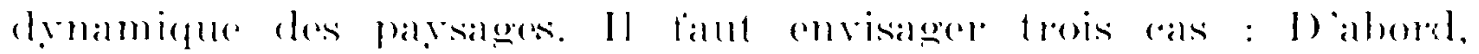
les éostestemes en rhexistaside hiorelimatigue dont la geomorphosenese est actire par l'homme. Ensuite, les geosestemes mareginaux on « mosä̈que », cost-a-dire avere des geofacies en rhexistasio

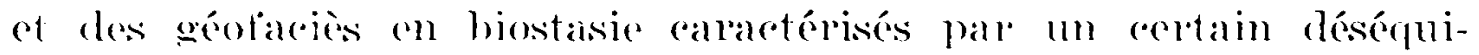
libre of une certaine fiagilite naturelle (Phot. 1). L'exemple type

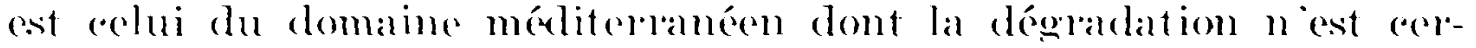

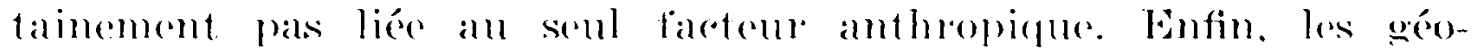

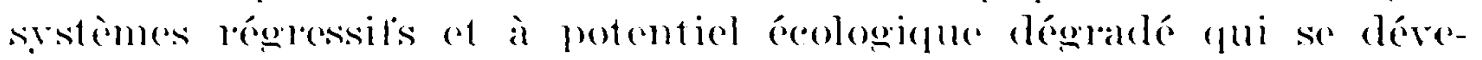
loppent par intervention anthropique an sein de paysalges en pleine biostasie (eertaines eultumes de plantation en économie coloniale).

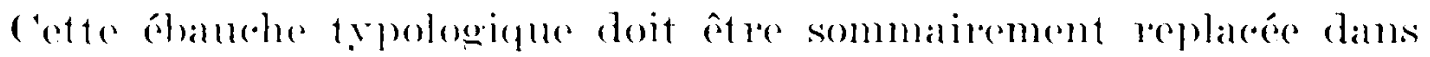
la double perspective du tempse et de lespace.

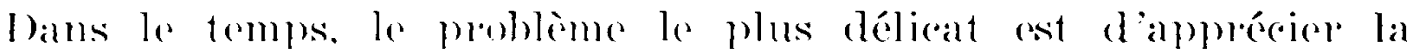

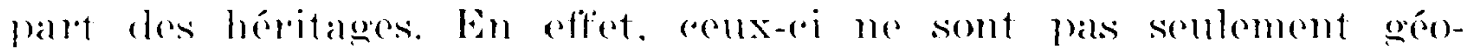
morphologigues of pédologigues malis alussi floristigues ot anthropirfues. Il laudrat pouroir recomstituer la rhatme historigue des

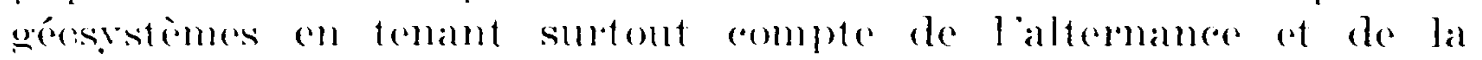

(21) L’érosion "épidermique " avait déjà été définie sous le nom d'érosion «biologique " (G. BI:RTRAN1), ibid. note 19, pp. 140-143). Mais ce qualificatif itait ane source de confusion. 
durese respective des phases d'épuilihre biologique ot des phases dartivité géomorphogénique. Tes résultats combinés de la pollenanalise, de lexamon des dépôts supepfieiels et des paléo-sols, de létude de laretion humaine depuis les débuts de la vie pastolale

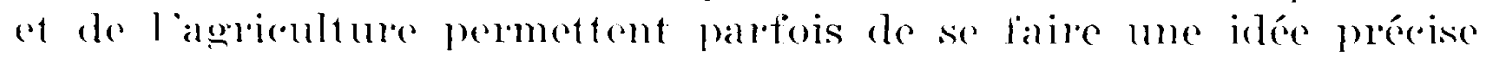

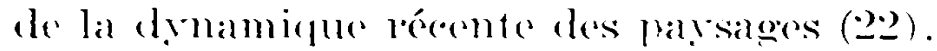

Dans lespace, löntrication des gésystomes est un lat genéral.

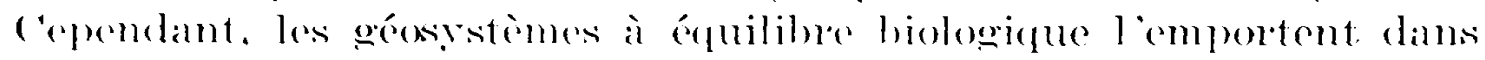
les zomes temperées ef tropicales humides ainsi que dans rertaines régions de plaine. Ial halute montagne of les diagonales alrides

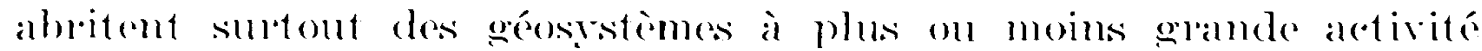
gémomphogépigue. I exploitation anthropique est en train de bonleverser cotte distribution essentiellement bio-celimatique an entendant les geosistimes an désépuilibu hiologique. Mais loposion

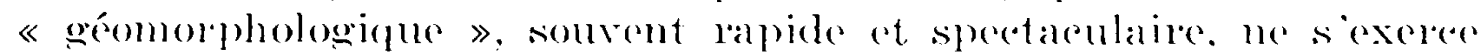
en lait que sur des surfaces réduites. Par contre, le véritable danger du point de vue de lamenagement de l'espale est lónosion «epidermique qui, de facon somvent insidieuse, wrignote la pellirule vivante des velsants dams des secteuls etemdus sans quion $y$ prête une réelle attention. Létude de la distribution spatiale des

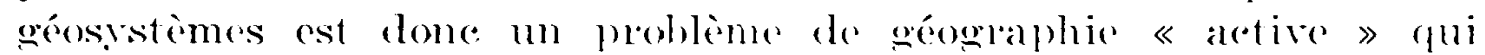
vient rentorece l intérêt de la recherche cartographicfue.

\section{La cartographie des paysages}

Lal representation antographique des paysages axige no inven-

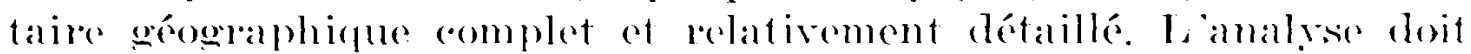

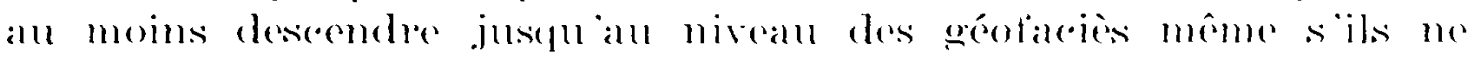
doirent pas figurer sur la carte. Iossentice du travail seffecture

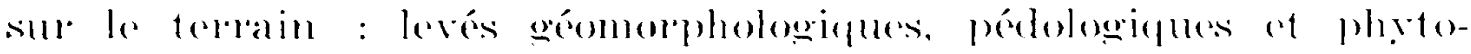

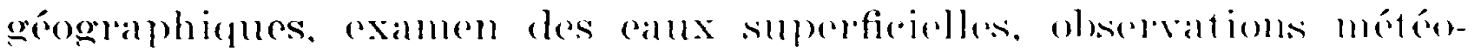

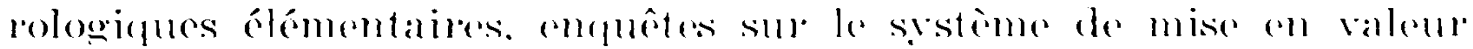

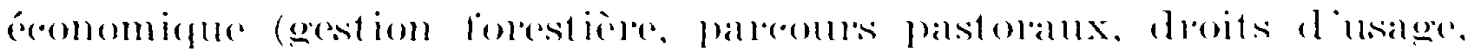

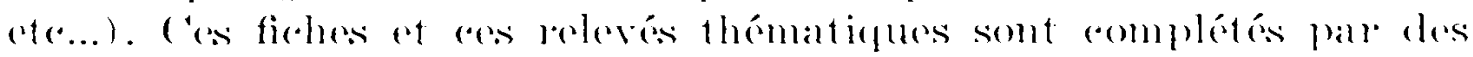

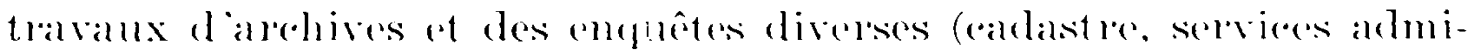

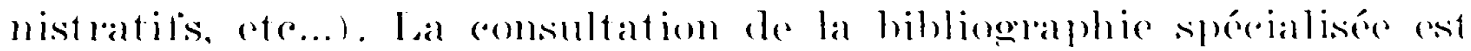
bien entendu indispensable. mais elle est somvent difficile a ntilisele

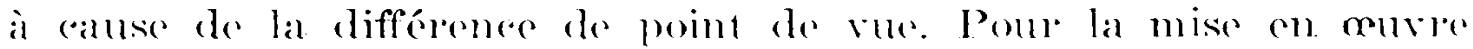

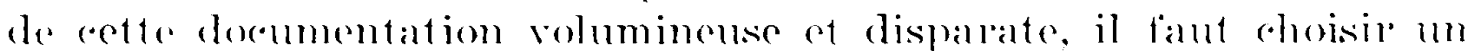

(22) Lat region cantabrique se prefe asses bien at cette recherche grace atux travaux des prehistoriens, des palynologues et des phytosociologues. 
fil directeur. Il est fourni par le tapis végétal dont le relevé sustématique au $1 / 50000$ suivant une méthode simplifiée, intermédiaire entre celle du servies de la Carte de la végétation au $1 / 200000$ de la France et celle de la Carte de la végétation au 1/100000 des Alpes de P. Ozenda. sert de base à la cartographie olobale des parsalges. L interprétation des photographies aériommes eonstitue un appoint précieux car elle foumit une vision synthétique ef instantaméc des parsages. Des essais cartographicques ont été réalisés à plusiours échclles (203) :

A moycmue échelle $(1 / 100000$ ef 1200000$)$, on peut cartographier les géoșstèmes de facon satisfaisante à condition de jenonece à laccumulation des signes analytiques of de choisir une replésentation synthétiquo. Chaque géosistème roprespond à uno plage dont la couleur ot la trame dams la couleur sont choisios on fonction de la drumamique du géestisteme exomple : heu pour les wésystemes climaciques, vert pour les géoststimes paraclimaciques.

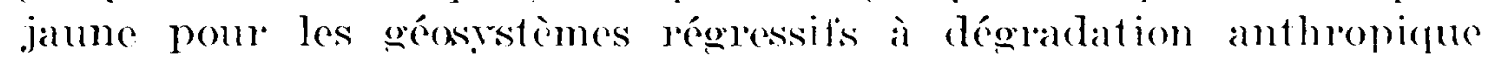
dominante, rouge pour les géasystemes à évolution essentiollement sémolphologique). Tas jenx de trame permettent de muancere eotte 1.rpologie. Sur la carte an 1/200000 des montagnes amtabriques contrales (courrant environ $6000 \mathrm{~km} 2$ ). on a dételminé trente-deux géosistimos (24).

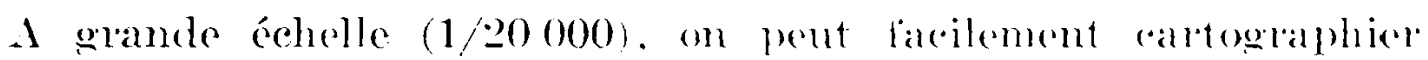
les géofaciès à löntélieur des géosestèmes. I a conlent ou la nuaner dans la couleur de chaque géosysteme indique la situation dýna-

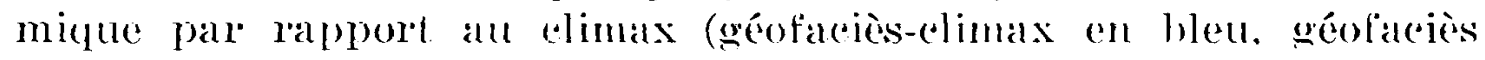
dégradé en jaune on en rouge). (On peut aussi choisir un thème, par exemple, les rapports cutre le couvert régétal et l'érosion « épidermique».

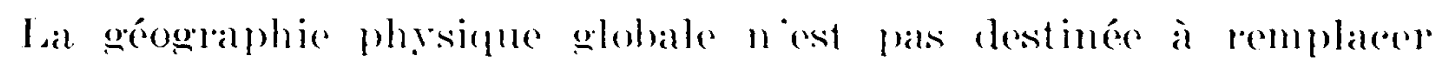
ni même à concurrencer les etudes spécialisées traditiommelles dont d'ailleurs olle se nomreit. Fille ronstitue mo recherehe parallele gui rapploche, eomtronte ot romplete les dommés de lamalyse et

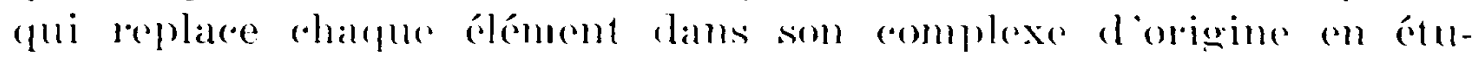
diant plus spécialement les ambinatisoms geoserphipues of lenr dronamigue globale. Sa fonction essentielle est donc de « décloisommer » la géographie phrsicfue traditiommelle et de faire directemont alppel aux soiences hiologiques ot alux seiences humaines. De plus, en dommant le moxen de déreriere dexplicfuer et de classer

(23) On s'est contenté de rappeler ici la méthode suivic et les résultats obtenus au cours des recherches de these et de direction de diplomes.

(24) Cette carte au 1200000 en sept couleurs existe soms forme de maquette et cloit être acheréc dans le courant de 1968. 
seientifinuement les paysalges, elle somve tout naturellement sur

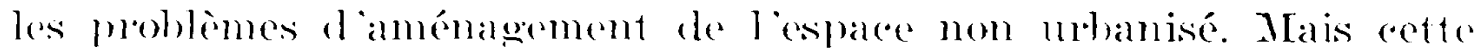
etude eqlobale des milienx natueds ne peut etre eonduite par les

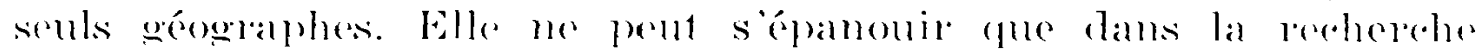
ol la réflexion interdisciplinatres.

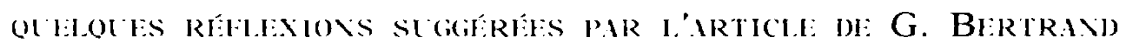

L'article de G. Bi:RTraxb offre un immense mérite : celui d'aborder de front les difficiles problemes de méthodologie qui ont été beaucoup trop laissés de côté par les Géographes en général, surtout les spécialistes de Géographie Physique, qui semblent aroir un reritable gout vicieux pour travailler ì l'arcuglete. C'est pourquoi il suggere bien des reflexions.

1. Notion de passage.

Certes, k paysage est essenticl en Géographic. Mais la Géographic-Paysage a fait long feu. En effet, on ne peut fonder une science seulenent sur des descriptions et des apparences. Qu'est l'anatomie en médecine?

La réalité géographique doit se définir a partir de dvnamismes. Ce ne sont pas des points de l'espace que nous etudions, que nous derons définir, elasser, comparer, mais des cottrbes. Il ne s'agit la que d'une banale application particuliere d'un principe beaucoup plus général : la matière ne se délinit-elle pas, en physique, comme une énergie? Nous devons nous lancer dans cette roie. Et c'est d'ailleurs ce que fait G. BrirtriNi.

Le taxon phrsico-géographique, quelle que soit sa dimension, se caractérise par une certaine structure des divers facteurs de causalité qui sont a l'origine de son existence. C'est un certain systeme d'interactions, décrivant une certaine courbe d'évolution, courbe qui peut s'infléchir du fait de modifications dans les rapports entre facteurs, soit facteurs internes, faisant partie du svstème lui-mêne, soit facteurs externes. On retrouve cela aussi bien au niveau de la climatologie dynamique, qu'à celui de la géomorphologie, qu'à celui de l'hydrologie, el, bien entenclu, at un niveau de complexité supérieur, en biogéographic.

Le rổe du gcographe est de dimonter es complexes, ces combinaisons, pour reprendie un rocabulaire fructueux de notre Maître A. Cholder. Le pavsage n'en est qu'un aspect extérieur, changeant, formel. Certes, en matière d'étude des êtres vivants, on hésite encore et les différences de conception sont profondes entre les écoles de Toulouse, plus descriptive, et de Montpellier, plus dronamique, plus orientéc vers l'́cologie.

Raisons de plus pour que les géogmaphes sinteressent au probleme.

2. Niveanx taxolnomiques.

Encore une notion essenticlle, et trop négliges. Les drnamiques, les tissus facteurs de causalité avec leurs actions et rétroactions, ne sont pas de même nature stivant l'ichelle considerese. Je m'érertue de le montrer depuis des annécs a propos du cas particulier de la géomorphologie mais le problenne a une importance bien plus générale. La notion déchelle intervient de maniere tranmique dans les dynamiques.

Il y a une hicharchic cles lacteurs de causalité des interactions. La géomorphologie drnamique fonetionne dans des eadres stracturatex de niveatu taxonomique supéricur. commandés par la géologie, et, derriere elle, par la constitution géophysique du Glohe. Mais, de son coté, la géomorphologic commande la formation et lérolution des sols. Les gloupements régétaux, it lichelle du $1 / 20000-1,50000$ sont sous lestroite dépendance du facteur geomorphologique (ou mieus, des drnamiques geomorphologiques), mais it Fichelle du $1: 100$ ou mene du $1 / 1000$. ils offent des hétérogenéites que la geomorphologic est incapable d'explicutei : la maille des analises qu'elle effectue est trop grossicre, et ce, non pas par suite d'une insuffisante maturité méthodologique mais nar suite des décalages d'échelle entre sistiones d'interactions. rechniquement, il est possible de dresser une rante

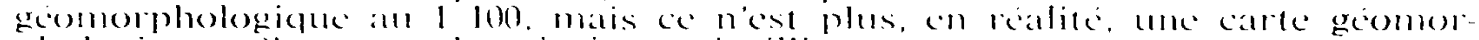
phologique. (eit une description pointilliste. 
Les mêmes structures logiques affectent également l'aspect temporel des phénomenes. Ia notion de continu et discontinu, essentielle, n'est jamais valable qu’a une échelle temporelle donnéc. I.exemple du cinéma, qui donne une modification apparemment continue de l'image a partir de la succession d'images fixes, est particulierement pédagogique

Mais it y a plus. Chaque taxon physico-gegraphicte se delinit non seulement par une drnamique propre, mais aussi, par un certain degré de permanenec. qui commande sa persistance dans les sumivanes. Peu de choses ont éte précisés dans ee domaine essentiel. Or, le degré de permanenes nest pas directement lie a la dimension. Il est des objets tres petits qui sont dousis clume aptitude considerable a la permanence, comme le grain de quats. imousse-luisant. Il est des objets tres grands, également fort permanents, comme certaines chaines de montagnes (les Andes). Chaque drnamique d'un? certain niveat taxonomique est prise dans une drnamique plus vaste, qui commande, dans une large mesure, son degré de duabilité Cute notion est essenticlle, particulierement en biogeographie, car elle permet d'analyser les survirances. le parsage tel que nous le royons, et P. BIrot a insisté sur ce point, est un palimpseste. Il est constitue d'élements d'age dilférent, de dyamique diflérente, de degre de durabilite differents. A cote des echelles sipatiales, il faut recourir aux échelles temporelles et, de plus, fatire une réritable analise démographique des drnamiques.

lne description pure tourne vite at kakédoscope. Fondé seulement sur des appatences, elle multiplie les catégories et aboutit al des classifications inuti. lisables, dont la septieme Approximation americaine pour la classification des sols ofle un redoutable exemple. Au contraire, l'analyse drnamique permet de retrouver des familles de courbes, de nettre en lumiere des vantantes, des dirergences, des enveloppes et des limites.

En nous limitant rolontairement a ces deux themes, remercions G. BIRTR.NI) dont l'effort methodologique méritoire nous a suggéré ces riflexions et souhaitons qu'un trarail d'equipe permette enfin d'aborder ces problimes si importants et encore trop négliges.

J. TRICIRT.

Ristmí - Létude globale des nassages a dominante physique derait etre l'une des prococupations majeures du naturaliste et du géogranhe. La méthode proposéc tient compte a la fois de l'échelle temporo-spatiale. de la physionomie el de la drnamique des passages. Le systente taxonomique comporte six unites synthetiques emboîtées : la zone, le domaine, la région llaturelle, le "géusssieme ", le « géofaciess" et le "géotope ". Chacune de ces combinatisons dialectiques comporte un potentiel écologique, une exploilation biologiglie ct se définit essontiellement par un s sistemé d'évolution : qui integre le svsteme d'érosion traditionnel, la dinamique proprement biologique et laction anthropique. Une typologie dramique permet de classer les parsages en fonction de leur mobilité par rapport au climax général (érolution progressire, régressive, stabilité). Cette méthode se complete par une cartographie systematique des parsages au niveau des géosystemes et des géofacies qui débouche tout naturellement sur les problemes d'aménagement de lespace non urbanisci.

Rrsintax. - Paisaje y geografia fisica slobal : Ensayo de mo'todologia. El estudio sintético de los paisajes en que predomina lo físico tendria que ser una de las mavores preocupaciones del naturalista v del gégrafo. El método que aqui se propone tiene en cuenta la escala temporo-spacial, la fisionomía y la dinamica de los paisajes. El sistema de classificacion comsia de seis mindades sinteticas sobrepuestas : la «zone ", el "domaine", la "région naturclle", el « géosystène", el "géofacies " v el "géotope ". Cadat una de estas combinaciones dialécticas incluve un potencial ecológico. una explotación biológica $y$ se define esentialmente por un sistema de erolucion que asimila el sistema de erosion tradicional, la dinámica meramonte biologica y la accion antropica. Una tipologia dinamica permite clasilicar los paisajes segrin su mobilidad en relación con el climax general (erolucion progressiva, regressiva, estabilidad). Viene rematado este metodo por una cartogralia sistematica de los paisajes a la altura de los "géosystinies $" y$ de los « géofacies ", la cual empalma naturamente con los problemas de la organisacion del espacio no urbanizado. 